\title{
A coastal retracking system for satellite radar altimeter waveforms: Application to ERS-2 around Australia
}

\author{
X. Deng ${ }^{1}$ and W. E. Featherstone ${ }^{2}$ \\ Received 3 May 2005; revised 18 November 2005; accepted 3 March 2006; published 13 June 2006.
}

[1] Satellite radar altimeter-derived sea surface heights (SSH) are in error in coastal regions due, in part, to the complex nature of echoes returned from rapidly varying land and sea surfaces. This paper presents improved altimeter-derived SSH results in Australian coastal regions using the waveform retracking technique, which reprocesses the waveform data through a "coastal retracking system". The system, based upon a systematic analysis of satellite radar altimeter waveforms around Australia, improves SSH data from several retrackers depending on the waveforms' characteristics. Central to the system is the use of two techniques: the least squares fitting and the threshold retracking algorithms. To overcome the problem of fading noise, the fitting algorithm has been developed to include a weighted iterative scheme. The retrackers include five fitting models and the threshold method with varying threshold levels. A waveform classification procedure has also been developed, which enables the waveforms to be sorted and then retracked by an appropriate retracker. Two cycles of $20-\mathrm{Hz}$ waveform data from ERS-2 have been reprocessed using this system to obtain the improved SSH estimates. Using the AUSGeoid98 gravimetric geoid model as a quasi-independent reference, the system improves SSH estimates from beyond $\sim 22 \mathrm{~km}$ to beyond $\sim 5 \mathrm{~km}$ from the coastline.

Citation: Deng, X., and W. E. Featherstone (2006), A coastal retracking system for satellite radar altimeter waveforms: Application to ERS-2 around Australia, J. Geophys. Res., 111, C06012, doi:10.1029/2005JC003039.

\section{Introduction}

[2] The quality of sea surface height ( $\mathrm{SSH}$ ) measurements from satellite radar altimetry in coastal regions is hindered not only by less reliable geophysical and environmental corrections [e.g., Fernandes et al., 2003; Chelton et al., 2001], but also by the noisier radar returns from the generally rougher coastal sea states and simultaneous returns from reflective land and inland water [e.g., Mantripp, 1996; Andersen and Knudsen, 2000]. For instance, ERS-2 altimeter SSHs can be contaminated by these factors up to a maximum distance of $\sim 22 \mathrm{~km}$ offshore the Australian coast [Deng et al., 2002]. As such, many scientists avoid the use of SSHs in coastal regions [e.g., Nerem, 1995], typically beyond 20-50 km of the coast [Strub and James, 1997].

[3] The profile of backscattered power (i.e., waveform) from a satellite-borne radar altimeter is described by the Brown [1977] model, which is based on specular reflection from the open sea surface. As illustrated in Figure 1, the ideal waveform consists of three main parts: thermal noise, leading edge and trailing edge. If the waves on the ocean

\footnotetext{
${ }^{1}$ Discipline of Civil, Surveying and Environmental Engineering, University of Newcastle, Callaghan, New South Wales, Australia.

${ }^{2}$ Western Australian Centre for Geodesy, Curtin University of Technology, Perth, Western Australia, Australia.

Copyright 2006 by the American Geophysical Union. 0148-0227/06/2005JC003039\$09.00
}

surface are assumed to be linear (which is not necessarily true in the coastal zone), the corresponding statistics of surface elevation and slopes are Gaussian (i.e., the oceansurface height distribution is symmetric about some mean value). Therefore, the altimeter waveform is an odd function relative to the midpoint (i.e., half-power point) on the leading edge of the returned waveform, and the range to the at-nadir sea surface corresponds to this midpoint. The Brown [1977] model is thus the general function used by on-satellite data processors [Chelton et al., 2001].

[4] Close to the coastline, however, the altimeter simultaneously "views" both water and land surfaces. These two scattering surfaces may have different elevations, but the shortest range to the altimeter depends on the distance to the shoreline, and the slope and radar reflectivity of the land [Brooks et al., 1997; R. L. Brooks, personal communication, 2002]. The on-satellite tracking of the midpoint on the waveform's leading edge is sensitive to the width of the middle gate, which is centered on the tracking gate and consists of averages over two or 16 waveform samples. The middle-gate along-track footprint for $20 \mathrm{~Hz}$ measurements varies from $8.5 \mathrm{~km}$ to $15 \mathrm{~km}$ for ERS-2 depending on the presence of surface roughness [cf. Chelton et al., 2001, p. 36; Deng et al., 2002]. As this footprint gets closer to the coastline, the slant range to reflectively higher land may be shorter than that from the nadir ocean surface. Since the altimeter measures the shortest range (first return), the land return within the footprint contributes to the power received by the altimeter, 


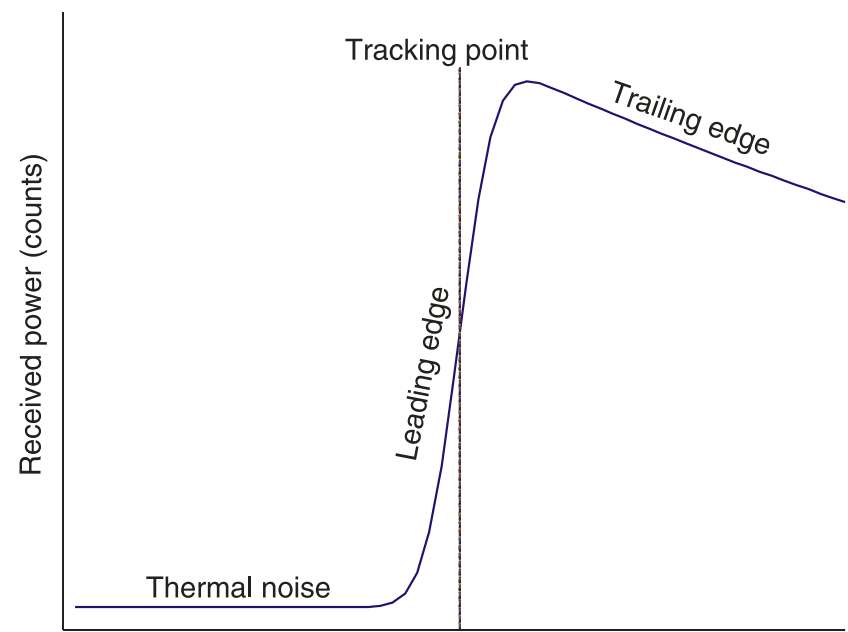

Time or gate

Figure 1. Schematic altimeter mean return waveform over sea surfaces. The ERS-2 waveform is recorded in 64 range bins or gates. The spacing of the gates is $3.03 \mathrm{nsec}$ or 454 $\mathrm{mm}$. The leading edge usually spans $3-4$ range bins.

thus contaminating the returned waveform. The shape of the waveform can also be significantly affected by the generally rougher coastal sea states, or from inland water. For example, calm (i.e., more radar-reflective) water surfaces near the coastline, such as bays and estuaries, make the returned power peaked. These land-contaminated and peaked waveforms can be difficult to track using only the open-ocean Brown [1977] model.

[5] Retracking altimeter waveform data in coastal regions to obtain improved SSHs has been the subject of comparatively little study. Thus far, two approaches have been applied: the fitting and threshold techniques. The first fits an analytical waveform model to the observed waveform data to determine more accurate range estimates [e.g., Anzenhofer et al., 2000]. This fitting function is based upon the 5-parameter function developed by Martin et al. [1983], choosing either a linear or an exponential trailing edge. An alternative method used by Brooks et al. [1997] is a modified threshold retracking technique [cf. Wingham et al., 1986; Davis, 1997], which retracks the ocean return from the land-contaminated waveforms close to the coastline. To the authors' knowledge, most previously published retracking efforts in coastal zones use algorithms developed for ice sheets, and only a single retracker is used. However, it will be shown in this paper that using only a single retracker limits the precision of recovered SSHs due to the diverse waveform shapes in coastal regions.

[6] A comprehensive analysis of waveform shapes at the Australian coast led to the need to develop a "coastal waveform retracking system". The primary idea behind the system is that several retrackers must deal with the majority of the coastal waveforms, and they must complement one another. As a case study, the system is applied to the Australian coast using two cycles (42 and 43) of ERS-2 $20 \mathrm{~Hz}$ waveform data (March to May 1999). The SSH before and after retracking is compared with an external quasi-independent reference of the AUSGeoid98 gravimetric geoid model [Featherstone et al., 2001], which verifies the effectiveness of the system. The term quasi-independent reflects that altimeter-derived gravity anomalies were one of the data sources for this model.

[7] It is acknowledged that the instantaneous $\mathrm{SSH}$ is not equivalent to the geoid (loosely mean sea level). The difference between them includes the time-variant component (e.g., tides) and the time-invariant component (e.g., the ocean surface mean dynamic topography (MDT)). The former can be removed by averaging, and the latter can be removed by a MDT correction to the SSH. However, the MDT models are usually designed for resolving basin-wide scales and hence are highly smoothed [e.g., Levitus, 1982]. Applying such a MDT correction in coastal regions may cause an additional error to the $\mathrm{SSH}$, which might be larger than the errors of other geophysical and environmental corrections. Therefore, the MDT was not applied to the $\mathrm{SSH}$ data in this study. Assuming that the MDT is a bias in the coastal zone, the verification of any improvement in the SSH will be seen in the standard deviations (STD) of the mean difference, with a smaller value indicating an improvement in the SSH.

\section{Costal Waveform Retracking Design and Implementation}

\subsection{System Design}

[8] Retracking is a procedure of waveform data postprocessing that aims to improve parameter estimates over those given as part of the standard altimeter "geophysical data products". These parameters include the range correction due to the estimation algorithm used and the limited computational time on board the satellite [e.g., Hayne, 1980; Rodriguez, 1988]. It is determined through estimating the offset of the actual tracking gate, which is related to the midpoint on the leading edge (see Figure 1), from the predesigned tracking gate that is used by default during onsatellite processing. This correction is then applied to the range calculated by the onboard algorithm.

[9] Because of the presence of various waveform shapes in coastal regions (see section 3.2), a coastal waveform retracking system, which consists of different retracking algorithms, should be considered when attempting to extract the precise SSHs from these land-contaminated waveforms. We have found that these are the fitting functions of the ocean, 5- and 9-parameter models, and threshold retracking algorithm (see Appendix A).

[10] The ocean model (equation (A1)), without the nonlinear ocean wave parameter, has been used as a main retracker in this system due to its clearly physical description of the ocean surface. By quantitative comparison to the 5-parameter model (equations (A6) and (A9)), the slope of the trailing edge modeled by the 5-parameter model has a larger range of variation than the ocean model (see Appendix B). This advantage makes the 5-parameter model more capable of fitting non-ocean-like or irregular waveforms in coastal regions than the ocean model. Thus, the 5-parameter model replaces the ocean model for irregular-shaped waveforms in our system.

[11] To deal with peaked waveforms reflected from calm coastal or inland water surfaces, the threshold retracking technique with 50\% threshold level (Appendix A2) was used. However, it is found that the $50 \%$ threshold level 


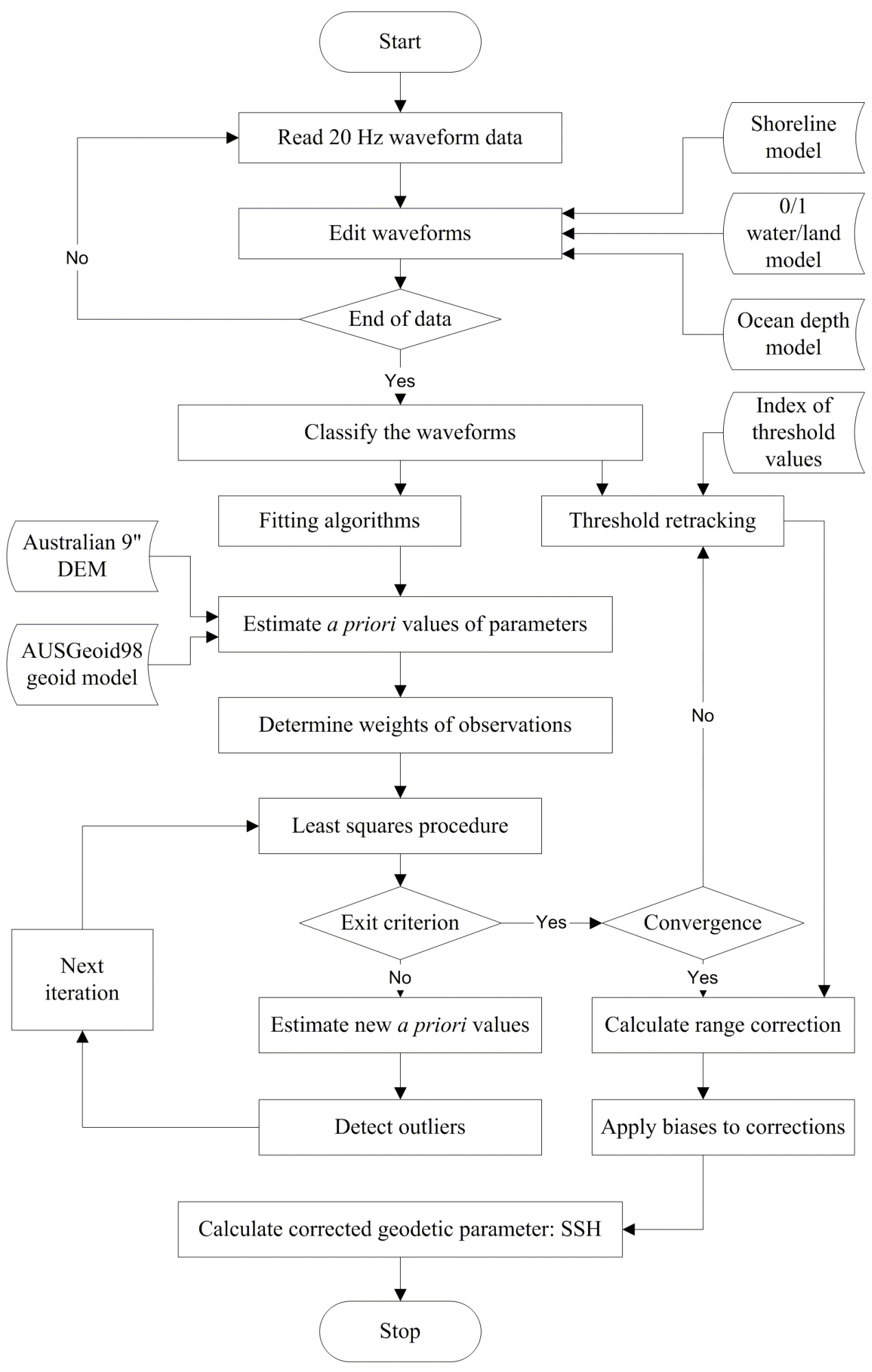

Figure 2. Block diagram of the proposed coastal retracking system.

cannot always give improved results, particularly in the area closest to the coastline where peaked waveforms are more prevalent. To validate the appropriate threshold level, a statistical analysis was performed to suggest the quality of the retracked SSH data. This turned out a detailed selection of the appropriate threshold levels (see section 2.3). A variable threshold level of $50 \%$ or $30 \%$ depending on the waveform shape is finally used in the system.

[12] Since valid SSH data can only be recovered from ocean returns, it is not necessary for our system to reprocess waveforms dominated by land returns. However, it is significant that the system can correctly categorize the 


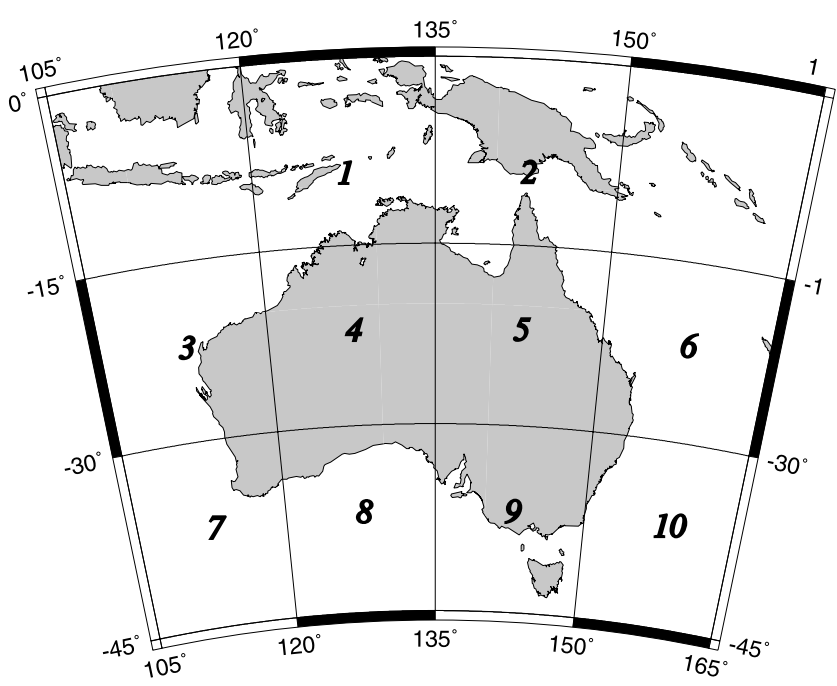

Figure 3. Ten $15^{\circ} \times 15^{\circ}$ coastal areas around Australia (Lambert projection).

waveforms, so that they can be retracked using a more appropriate retracker. This has generated an additional waveform classification stage to sort waveforms based on their different shapes, and thus indicate which retracker should be used for each. When retracking costal waveforms using all possible retrackers, improved SSHs result, but biases exist among different algorithms. Thus, an algorithm assessment has been implemented to analyze and estimate these biases (see section 2.4).

[13] Finally, Figure 2 illustrates how coastal waveforms are reprocessed to give the corrected SSH data: a specific retracker (fitting or threshold) is applied to each waveform based upon the earlier classification. When using the fitting algorithm, an adequate fitting function must be selected and the iterative nonlinear fitting procedure is used. Since a linear solution to a non-linear problem is sought, the fitting algorithm does not always work [Zwally et al., 1990; Davis, 1995]. Therefore, the threshold retracking replaces the iterative least squares fit to compute the retracking correction if and when the fitting procedure fails. Threshold retracking works both for peaked waveforms and those that fail with the fitting algorithm. Also, the system automatically selects the appropriate threshold level for each waveform depending on its categorized shape.

\subsection{Data Weighting and Outlier Detecting}

[14] An appropriate weight scheme is essential when using the fitting algorithm. In general, the trailing edge shows more obvious undulations than any other parts of the waveform due to the "fading" noise, which is caused by the incoherent superposition of signals from different reflecting facets [Partington et al., 1991; Quartly and Srokosz, 2001]. The noise in the trailing edge greatly influences the iterative fitting procedure and accurate results may not be estimated. To solve this problem, two approaches are usually used. The first is to average waveforms in the time span of several seconds to reduce noise, and then to fit a model to this averaged waveform [e.g., Hayne and Hancock, 1990; Fairhead et al., 2001]. The second is to give less weight to the waveform samples in the trailing edge [Zwally et al., 1990; Brenner et al., 1993; Anzenhofer et al., 2000].

[15] However, the averaging procedure is not always appropriate in coastal regions, because true ocean waveforms will be distorted by land-contaminated waveforms within the averaging window. The approach of down weighting the trailing edge, such as the a priori weights $\left(p_{i}^{0}\right)$ scheme used by Anzenhofer et al. [2000], cannot completely overcome the problem caused by undulations in the trailing edge. Therefore, an outlier detection approach from an iterative weight scheme was developed and used.

[16] In this iterative procedure, the initial least squares adjustment is conducted using the a priori values and a priori weights $\left(p_{i}^{0}\right)$. After the first adjustment, a new weight function $w_{i}$ is given as [e.g., $L i, 1988$ ]

$$
w_{i}= \begin{cases}\frac{1}{\left|v_{i}\right|} & \text { for }\left|v_{i}\right|>0.7 \sigma_{0} \\ \frac{1}{0.7 \sigma_{0}} & \text { for }\left|v_{i}\right| \leq 0.7 \sigma_{0}\end{cases}
$$

where $v_{i}$ and $\sigma_{0}^{2}$ are estimates of the parameter correction vector and unit weight variance, respectively. The next step then is to determine the weight $\left(p_{i}^{j+1}\right)$ for the next adjustment using $w_{i}$ as follows:

$$
p_{i}^{j+1}=p_{i}^{j} w_{i}
$$

where $j$ means the $j$-th iteration in the adjustment. In the meantime, the parameter estimates take the place of the original estimates; the entire cycle is repeated to produce improved estimates. In this way, the observations considered to contain the outlier will be downweighted but still be kept in the data set, while non-outlier observations will maintain full weight after each iterative cycle.

\subsection{Selection of the Threshold Level}

[17] There are two concerns related to the selection of the threshold level. The first is that threshold values should be higher than both the noise and the spectral leakage in the start/end gates. The second is that the values should be sufficiently lower than the sought-after ocean returns. Brooks et al. [1997] determine different threshold values for 18 TOPEX ground tracks near land based upon a visual examination method. These values were then used to retrack the coastal waveform along the same satellite pass. This method is advantageous because it accounts for the power backscattered from different reflecting surfaces. However, because an automatic selection of the threshold level is not available, this restrains the technique from retracking the wide range of waveforms in coastal regions.

[18] Considering the various waveform shapes in the coasts, four threshold schemes are investigated before arriving at the final threshold level in this study. They are as follows: (a) Fixed counts, which is defined as 50\% of the mean-waveform amplitude in counts. (b) $50 \%$ of the waveform amplitude. (c) $30 \%$ and $50 \%$ of the waveform amplitude. The $30 \%$ waveform amplitude is selected to retrack waveforms within $0-5 \mathrm{~km}$ from the coasts, while the $50 \%$ of the waveform amplitude is used after $5 \mathrm{~km}$. (d) Variable threshold level. If the waveform classification indicates a 


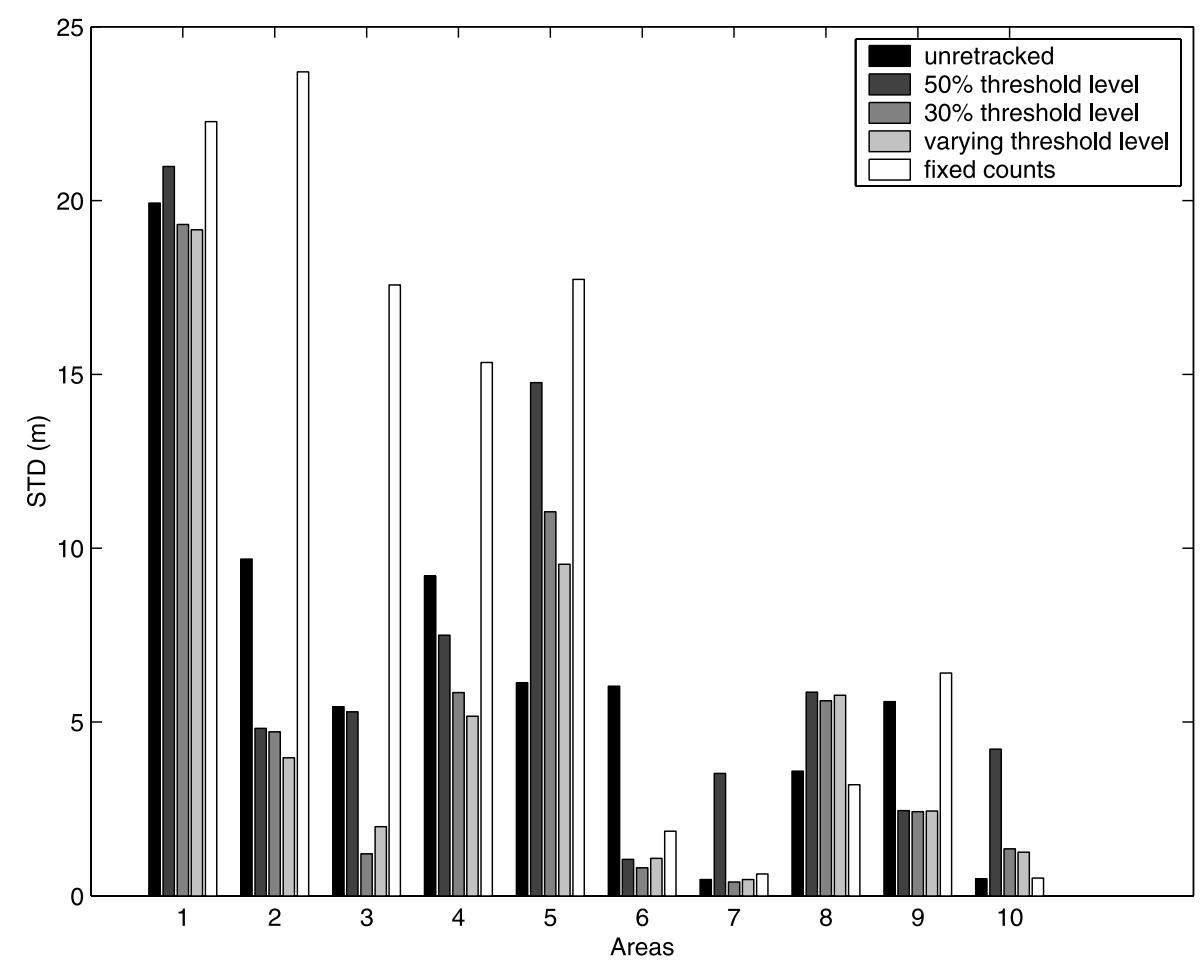

Figure 4. STDs of the mean differences in ten $0-5 \mathrm{~km}$ areas from the Australian coastline. Waveforms are threshold retracked using four threshold levels of (scheme (a)) fixed counts, (scheme (b)) $50 \%$ of amplitude, (scheme (c)) 30\% of amplitude, and (scheme (d)) varying level of $50 \%$ or $30 \%$ of amplitude.

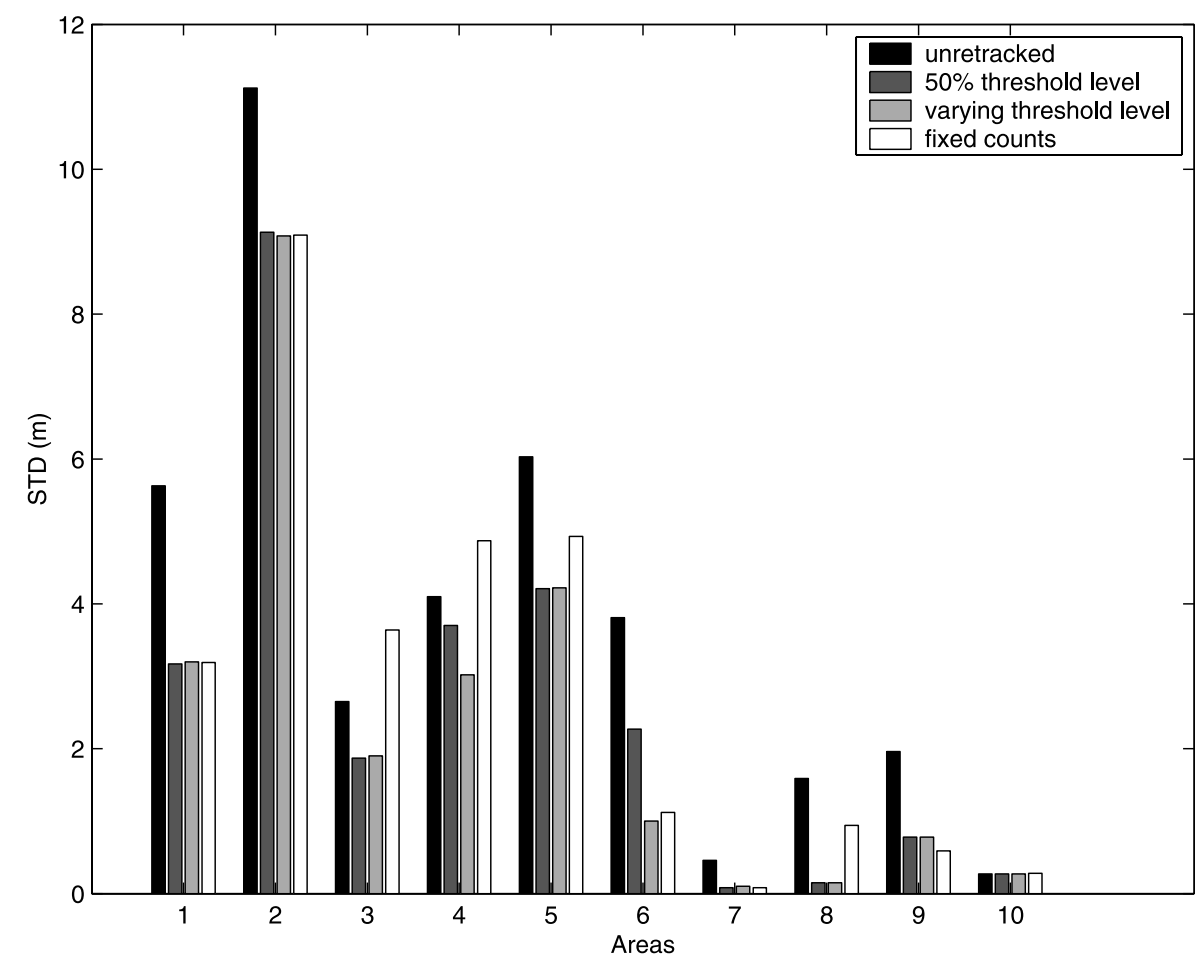

Figure 5. STDs of the mean differences in ten 5-10 km areas from the Australian coastline. Waveforms are threshold retracked using three threshold levels of (scheme (a)) fixed counts, (scheme (b)) $50 \%$ of amplitude, and (scheme (d)) varying level of $50 \%$ or $30 \%$ of amplitude. 
Table 1. Biases Between Different Retracking Algorithms From Fitting a Cubic Function to the ERS-2 SSH Differences Over an Ocean Area $\left(30^{\circ} \mathrm{S}<\phi<15^{\circ} \mathrm{S}, 105^{\circ} \mathrm{E}<\lambda<120^{\circ} \mathrm{E}, 50-350 \mathrm{~km}\right.$ From the Australian Coastline)

\begin{tabular}{|c|c|c|c|c|c|c|}
\hline \multirow[b]{2}{*}{ Retrackers } & \multicolumn{2}{|c|}{ Bias, cm } & \multicolumn{2}{|c|}{ Fit STD, $\mathrm{cm}$} & \multicolumn{2}{|c|}{ Number of Points } \\
\hline & Cycle 42 & Cycle 43 & Cycle 42 & Cycle 43 & Cycle 42 & Cycle 43 \\
\hline Ocean - Five parameter & -0.8 & -0.9 & 1.4 & 1.3 & 42470 & 53119 \\
\hline Threshold $(50 \%)$ - Five parameter & 56.1 & 57.1 & 1.7 & 2.3 & 10525 & 15131 \\
\hline Threshold $(50 \%)$ - Ocean & 55.9 & 56.3 & 8.4 & 7.6 & 40156 & 46483 \\
\hline
\end{tabular}

distorted waveform, the threshold level is set to $30 \%$ (or $20 \%$ depending on the reflecting surface); otherwise the $50 \%$ of waveform amplitude is set.

[19] In order to ascertain the appropriate threshold level, one cycle of $20 \mathrm{~Hz}$ ERS-2 waveform data (March to April 1999 ) in ten $15^{\circ} \times 15^{\circ}$ areas around the Australian coast were used (Figure 3). The AUSGeoid98 gravimetric geoid model [Featherstone et al., 2001] was used as external "ground truth" for the comparisons. Waveforms were threshold-retracked using the above four schemes. For each along-track altimeter SSH after retracking, the gridded AUSGeoid98 geoid height was bi-spline-interpolated to the longitude and latitude of the altimeter ground point. Descriptive statistics were computed from the difference between the SSH and geoid height. Figures 4 and 5 show STDs of mean differences in two distance bands of $0-5 \mathrm{~km}$ and 5-10 km around Australia's coasts (Figure 3), respectively.

[20] In both Figures 4 and 5, STDs are large in most of the areas before retracking. In the $0-5 \mathrm{~km}$ distance band (Figure 4), after threshold retracking using scheme (b), the STD decreases in five areas, but increases in the other five. The reason for this is that the mostly varying land topography and still water can heavily contaminate the waveforms, so that many waveform shapes do not follow the ocean model. This suggests that the $50 \%$ threshold level is not an appropriate selection for the waveforms within $5 \mathrm{~km}$ of the coast. After retracking using schemes (c) and (d), the STD shows improvements in seven areas. Of them, the results from the scheme (d) show the most significant improvement. In contrast, scheme (a) gives the least improvement, and even worse results in most areas after retracking. For areas 5,8 and 10, an appropriate threshold level of $20 \%$ was found. As can be seen from the ordinate scale in Figure 5 (5-10 km distance band), STDs decrease with increasing the distance from the coasts. All schemes, except for scheme (a), show similar results in most areas. This implies that less waveform contamination occurs in these areas, which agrees with results by Deng et al. [2002].

[21] The count-fixed level (scheme a) cannot follow the variations in the scattering surfaces. It assumes that the retracking amplitude of the ocean waveform does not change with varying surface roughness or topography. However, this is not the actual case, even over ocean surfaces. The $50 \%$ threshold retracking level (scheme b) is set too high to capture the ocean returns for the contaminated waveforms in coasts. Setting the $30 \%$ threshold level within $5 \mathrm{~km}$ from the coast and the $50 \%$ threshold beyond $5 \mathrm{~km}$ (scheme c) presents an improved result, but causes a step in the ranges after retracking where the threshold level suddenly changes. Nevertheless, the $30 \%$ (or $20 \%$ in some areas) and 50\% threshold levels (scheme d) over large areas of the coastal regions appear more reasonable (Figures 4 and 5).

\subsection{Assessment of Biases Among Retracking Algorithms}

[22] In order to investigate the biases among different retrackers, ERS-2 waveform data over an open ocean area $\left(50-350 \mathrm{~km}\right.$ from the coastline, area 3 in Figure $3: 30^{\circ} \mathrm{S}<\phi$ $<15^{\circ} \mathrm{S}, 105^{\circ} \mathrm{E}<\lambda<120^{\circ} \mathrm{E}$ ) were retracked and analyzed using the 50\% threshold level, the ocean model and 5parameter model. The 5-parameter function with an exponential trailing edge was not used, because the results of Anzenhofer et al. [2000] indicate that the bias between the 5-parameter functions with the linear and exponential trailing edges is insignificant $(\sim 1.3 \pm 10.8 \mathrm{~cm})$. Retracked SSHs are used to compute the along-track SSH differences between different retrackers.

[23] A cubic polynomial function is fitted to all $\mathrm{SSH}$ differences. The linear term is used as the bias estimate, and biases for cycles 42 and 43 are listed in Table 1 . The bias between 5-parameter and ocean fitting models is small and almost statistically insignificant. However, significant biases of $\sim 57 \mathrm{~cm}$ and $\sim 56 \mathrm{~cm}$ are found between the $50 \%$ threshold algorithm and 5-parameter model and ocean model, respectively. As such, these retracked ranges from 5parameter and ocean models are longer than those from $50 \%$ threshold retracking. The biases in Table 1 also indicate a good agreement about the bias estimates from two cycles of ocean waveform data.

[24] The biases between the fitting and threshold retrackers are caused by the algorithm itself [Fairhead et al., 2001]. Threshold retracking takes no account of noise in the waveform (especially in the trailing edge), and how this noise affects the leading edge from one waveform sample to the next. The fitting algorithm is still affected by noise in the trailing edge. Thus, the bias problem results from the effect of noise in the fitting algorithm, as well as too simplistic assumptions in the threshold retracking.

[25] The relative biases among retracking algorithms (Table 1) are then removed from the threshold-retracked range measurements. As the biases strongly depend on the algorithm adopted, they can also be determined by other methods. For example, Dong et al. [2002] validate the absolute bias between the altimeter-derived sea level and that derived by the tide-gauge measurements using a local geoid model, MDT model, and a GPS ellipsoidal height at the tide-gauges. This could be applied to estimate the absolute biases between different retracking algorithms. However, this remains an open issue for future work 


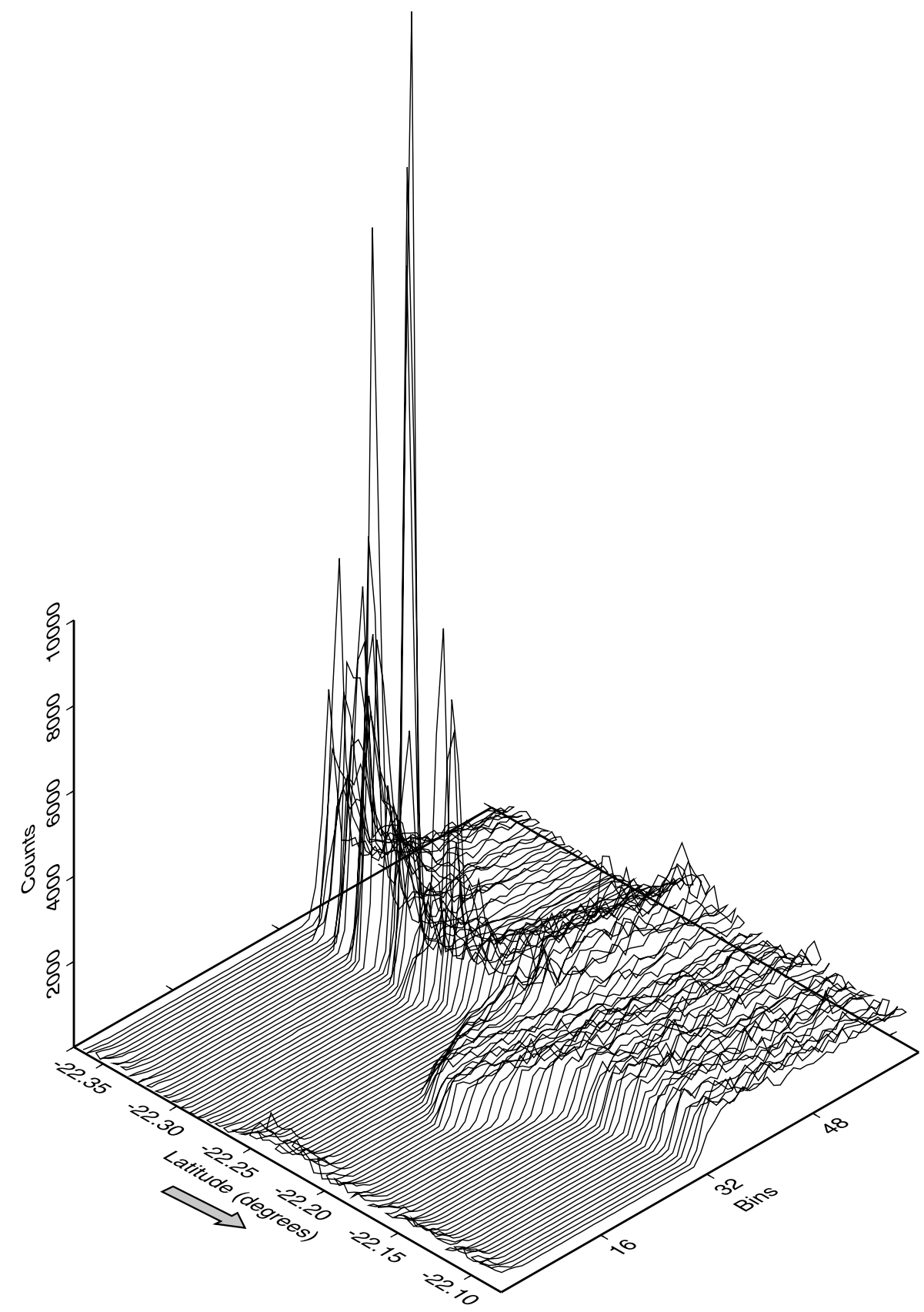

Figure 6. Waveform shapes vary as track 21636 leaving land to water. The high-peaked specular responses are due to off-nadir brighter (or calm) water. The waveform shifting $\left(-22.25^{\circ}<\phi<-22.15^{\circ}\right)$ is probably caused by the operation of the altimeter. The arrow beside the axis of presentation of the latitude indicates the direction of the satellite moving along the ground track.

because of limited availability of such data at the time of this study.

\section{Application to the Australian Coast}

\subsection{Data and Editing}

[26] As well as two cycles of ERS-2 $20 \mathrm{~Hz}$ waveform data, external data were used to provide information necessary for data editing and valuation. They are the GSHHS $(0.2 \mathrm{~km}$ resolution) shoreline model [Wessel and Smith, 1996], the Australian DEM $\left(9^{\prime \prime} \times 9^{\prime \prime}\right.$ resolution, version 2$)$, the DS759.2 $\left(5^{\prime} \times 5^{\prime}\right.$ resolution $)$ ocean depth model
[Dunbar, 2000], the Australian bathymetric model (30" resolution) [Buchanan, 1991], and the AUSGeoid98 ( $2^{\prime} \times$ $2^{\prime}$ resolution) gravimetric geoid model [Featherstone et al., 2001]. As stated, the MDT is not applied to the SSH data in this study, so any improvement in the SSH will only be seen in the STD.

[27] After retracking, geophysical corrections supplied with the waveform data by NRSC [1995] were applied to both retracked and unretracked range measurements to obtain the SSH. Since the electromagnetic (EM) bias correction caused by ocean surface waves is not supplied 
Table 2. Statistics of ERS-2 (Cycle 42) Contaminated Waveform Shapes in Ten Australian Coastal Areas (See Figure 3)

\begin{tabular}{|c|c|c|c|c|}
\hline $\begin{array}{l}\text { Waveform } \\
\text { Categories }\end{array}$ & $\begin{array}{l}\text { Percent of } \\
\text { Waveforms }\end{array}$ & $\begin{array}{c}\text { Mean } \\
\text { Distance From } \\
\text { Coastline, } \\
\mathrm{km} \\
\end{array}$ & $\begin{array}{l}\text { Mean Width of } \\
\text { Waveforms, } \\
\text { Bins }\end{array}$ & $\begin{array}{c}\text { Mean Peak of } \\
\text { Waveforms, } \\
\text { Counts } \\
\end{array}$ \\
\hline Ocean $^{a}$ & 99.97 & 168.04 & 25.8 & 1304.1 \\
\hline Ocean-like & 80.19 & 10.50 & 24.9 & 1380.3 \\
\hline Single pre-peaked & 4.64 & 2.31 & 10.7 & 2785.1 \\
\hline Single mid-peaked & 0.54 & 2.54 & 9.8 & 2615.0 \\
\hline Single post-peaked & 1.35 & 3.12 & 11.8 & 3027.0 \\
\hline Double pre-peaked & 0.55 & 3.08 & 14.8 & 2280.9 \\
\hline Double post-peaked & 0.73 & 2.15 & 16.1 & 2271.9 \\
\hline Multi-peaked & 0.18 & 2.30 & 13.0 & 2117.5 \\
\hline Sharp/High-peaked & 4.35 & 1.73 & 3.3 & 8439.5 \\
\hline Unusable & 7.51 & 6.03 & 34.7 & 1234.6 \\
\hline
\end{tabular}

with the waveform data products used in this study, it was not applied to the range measurements. Neither were the Doppler range corrections applied because most values were found to exceed the error criterion of $\pm 55 \mathrm{~cm}$ given by NRSC [1995].

\subsection{Waveform Classification}

[28] Contaminated waveforms [cf. Deng et al., 2002] around the Australian coast have been categorized, which is needed to choose the appropriate retracking algorithm. A detailed example of typical waveform categorization is given here from one ascending ground track 21636 off the northwest Australian coast (Figure 6). It is important to observe the departure of the mid-point on the waveform's leading edge from the expected tracking gate (i.e., 32.5 for ERS-2).

[29] Figure 6 shows ascending pass 21636 going from land to water. The waveforms present different shapes, such as high-peaked and land-contaminated, and then a change to typical ocean shapes at around $-22.1^{\circ}$ latitude. The waveform shifting in the range window is clear, which is probably due to the change of operation modes of the altimeter at the coast [Deng, 2004]. For most of the contaminated waveforms (Figure 6), a distinct leading edge is observable; in some cases, double ramps are apparent, and in others, high peaks with sharp ramp and rapidly decreasing trailing edge are apparent.

[30] The contaminated waveforms in ten $15^{\circ} \times 15^{\circ}$ Australian coastal regions (Figure 3) are categorized in Table 2. Most contaminated waveforms (80.19\%) have ocean-like shapes. The mean width of these waveforms is similar to that of ocean waveforms, whereas the mean peak value is larger. The remaining waveforms have single prepeaked $(4.65 \%)$ and high-peaked $(4.35 \%)$ waveform shapes. Others, such as single mid-peaked and post-peaked, double pre-peaked and post-peaked, and multi-peaked waveforms, fall in the range $0.73 \%-1.35 \%$. Although there is only a small percentage (12.34\%) of non-ocean-like waveforms, they are found closer to the coastline (1.73$3.12 \mathrm{~km}$ on average), indicating further that a retracking system containing several retrackers is necessary.

[31] In addition, from waveform categorization, highpeaked waveforms take a larger percentage of contaminated waveforms (from 5.4\% to 6.9\%) in north-west Australian coastal areas 1, 3 and 4 in Figure 3 because of the rugged coastline, complex sea states and inland/standing water [Thom, 1984].

[32] The percentages of waveforms retracked by fitting and threshold algorithms are listed in Table 3. It can be seen that $81 \%$ to $96 \%$ of waveforms in the study area can be retracked by the least squares fitting algorithm. The rest of

Table 3. Waveform Data Status and Percentage of the Waveforms Retracked Using Fitting and Threshold Retracking Algorithms in Australian Coastal Regions (Cycles 42 and 43)

\begin{tabular}{|c|c|c|c|c|c|}
\hline $\begin{array}{c}\text { Area } \\
\text { Number }\end{array}$ & Areas $^{\mathrm{a}}$ & $\begin{array}{c}\text { Number of } \\
\text { Data }\end{array}$ & $\begin{array}{c}\text { Unusual Data, } \\
\%\end{array}$ & $\begin{array}{c}\text { Fit, } \\
\%\end{array}$ & $\begin{array}{c}\text { Threshold, } \\
\% \\
\end{array}$ \\
\hline 1 & $120^{\circ} \leq \lambda<135^{\circ},-15^{\circ} \leq \phi<0^{\circ}$ & 10752 & 1.5 & 82.9 & 15.7 \\
\hline 2 & $135^{\circ} \leq \lambda<150^{\circ},-15^{\circ} \leq \phi<0^{\circ}$ & 10922 & 1.7 & 85.5 & 12.8 \\
\hline 3 & $105^{\circ}<\lambda<120^{\circ},-30^{\circ}<\phi<-15^{\circ}$ & 13448 & 1.7 & 86.5 & 8.6 \\
\hline 4 & $120^{\circ} \leq \lambda<135^{\circ},-30^{\circ} \leq \phi<-15^{\circ}$ & 6065 & 2.2 & 80.9 & 16.8 \\
\hline 5 & $135^{\circ}<\lambda<150^{\circ},-30^{\circ}<\phi<-15^{\circ}$ & 9682 & 2.1 & 88.0 & 9.4 \\
\hline 6 & $150^{\circ}<\lambda<165^{\circ},-30^{\circ} \leq \phi<-15^{\circ}$ & 3739 & 0.2 & 92.8 & 7.0 \\
\hline 7 & $105^{\circ}<\lambda<120^{\circ},-45^{\circ}<\phi<-30^{\circ}$ & 6055 & 7.4 & 88.6 & 4.6 \\
\hline 8 & $120^{\circ} \leq \lambda<135^{\circ},-45^{\circ} \leq \phi<-30^{\circ}$ & 12288 & 4.3 & 88.8 & 6.9 \\
\hline 9 & $135^{\circ}<\lambda<150^{\circ},-45^{\circ} \leq \phi<-30^{\circ}$ & 21672 & 2.6 & 90.3 & 7.1 \\
\hline 10 & $150^{\circ} \leq \lambda<165^{\circ},-45^{\circ} \leq \phi<-30^{\circ}$ & 4115 & 0.0 & 95.6 & 4.4 \\
\hline
\end{tabular}

${ }^{\mathrm{a}}$ Here $\phi$ and $\lambda$ are the latitude and longitude, respectively (see Figure 3). 
Table 4. Descriptive Statistics of ERS-2 $20 \mathrm{~Hz}$ SSH Differences Before and After Retracking $\left(d h=h_{r}-h_{g}\right.$, Cycle 42)

\begin{tabular}{lccccc}
\hline $\begin{array}{c}\text { Distance to } \\
\text { Coastline, } \\
\text { km }\end{array}$ & $\begin{array}{c}\text { Number of } \\
\text { SSH }\end{array}$ & $\begin{array}{c}\text { Mean, } \\
\mathrm{m}\end{array}$ & $\begin{array}{c}\text { Max, } \\
\mathrm{m}\end{array}$ & $\begin{array}{c}\text { Min, } \\
\mathrm{m}\end{array}$ & STD, m \\
\hline $0-5$ & 5074 & -0.79 & 9.25 & -9.99 & 2.35 \\
$5-10$ & 6517 & -0.20 & 9.43 & -9.82 & 1.31 \\
$10-15$ & 7416 & -0.24 & 6.62 & -8.15 & 0.99 \\
$15-20$ & 7313 & -0.25 & 7.43 & -6.89 & 0.71 \\
$20-25$ & 7728 & -0.30 & 7.71 & -8.38 & 0.57 \\
$25-30$ & 7496 & -0.28 & 5.69 & -9.13 & 0.57 \\
\hline
\end{tabular}

the waveforms (the last column) still require threshold retracking ( $\sim 4 \%$ to $\sim 17 \%$ for both cycles). The percentages of different retrackers used vary from area to area depending on the reflecting surface topography. As to the fitting algorithm from Table 3, $98.5 \%$ of waveforms can be fitted by the ocean or 5-parameter models. A maximum $1 \%$ of waveforms are fitted using the 5-parameter model with an exponential trailing edge. In addition, a maximum $0.4 \%$ of waveforms are fitted by the 9-parameter model with either a linear or an exponential trailing edge.

[33] The statistics corresponding to six 5-km-wide distance bands from the coastline has also been calculated. According to the results of both cycles, $65 \%$ and $35 \%$ of waveforms are retracked by the fitting and threshold algorithms in a distance band of $0-5 \mathrm{~km}$, respectively. From 5$10 \mathrm{~km}, 96 \%$ and $4 \%$ of waveforms were retracked by the fitting and threshold algorithms, respectively. As to the rest of four distance bands from $10 \mathrm{~km}$ to $30 \mathrm{~km}, 98 \%$ waveforms were retracked by the fitting algorithm, while $2 \%$ needed to be threshold retracked. Overall, the waveform shapes generally agree well with the typical ocean waveform beyond $10 \mathrm{~km}$ offshore.

\subsection{Analysis of the SSH Data Before and After Retracking}

[34] The comparison is performed by calculating the difference $d h$ between the retracked SSH $h_{r}$ and unretracked $\mathrm{SSH} h_{g}$ at the same location along each ground track. This difference $\left(d h=h_{r}-h_{g}\right)$ represents the sum of the bias of $\mathrm{SSH}$ data before and after retracking and the error removed by retracking. The mean and STD of the difference are calculated in six 5-km-wide bands from the coastline. Choosing different distance bands allows us to see how close to the coastline the altimeter ranges are improved by retracking. Results are listed in Tables 4 and 5 for cycles 42 and 43 , respectively.

[35] It is also found that biases exist between the $\mathrm{SSH}$ data before and after retracking. The computed biases are 30 $\mathrm{cm}$ between $50 \%$ threshold-retracked and unretracked SSHs and $-27.6 \mathrm{~cm}$ between fitting-function-retracked (ocean and 5-parameter models) and unretracked SSHs [cf. Deng, 2004, p. 166]. These biases are caused by the limitations on the altimeter's onboard computing power and the time taken to update the onboard processor to make its next range estimate. The result is range biases, which are a function of the significant wave height (SWH) and the off-nadir angle [Hayne, 1980]. The bias can be corrected from the instrument correction computed by ground data processing systems or by waveform retracking (G. S. Hayne, personal communication, 2002). However, the range still remains uncorrected in the waveform products supplied by NRSC [1995]. Therefore, while bias is removed from the retracked range measurements, it still affects the unretracked range taken from the waveform products. This is the most plausible reason for the bias between the SSH data before and after retracking.

[36] As mentioned in section 2.4, relative biases among retracking algorithms are applied to threshold-retracked $\mathrm{SSHs}$, so that the retracked $\mathrm{SSH}$ is based on a reference of the ocean model. As such, we need only be concerned with the bias of $-27.6 \mathrm{~cm}$ between SSHs before and after retracking using fitting functions. It should be noted that this bias is not applied to the individual SSH. Instead, it is applied to the mean difference between the SSHs before and after retracking in Tables 4 and 5 to analyze only the error removed by retracking. The STD of the SSH differences in Tables 4 and 5 decreases with increasing distance offshore. The STD decreases to $<1 \mathrm{~m}$ for distances $>15 \mathrm{~km}$ from the coastline. Because the comparison is conducted at the same along-track point and same time, the satellite orbit error, geophysical corrections and other errors cancel on taking the difference between the retracked and unretracked SSH. Therefore, large STDs indicate that the significant error occurs due to contamination near the coastline.

[37] If only considering the bias $(-27.6 \mathrm{~cm})$, the important amount of error removed by waveform retracking is $-51 \mathrm{~cm}$ and $8 \mathrm{~cm}$ for cycle 42 in distance bands of $0-5 \mathrm{~km}$ and $5-10 \mathrm{~km}$, respectively, while the results do not show a significant amount of error in the rest of the four distance bands. Similar results can be found for cycle 43, for which the amount of error in distance bands of $0-5 \mathrm{~km}$ and 5$10 \mathrm{~km}$ is $-51 \mathrm{~cm}$ and $14 \mathrm{~cm}$, respectively. This suggests that retracking can effectively remove the altimeter tracking error in coastal regions, particularly $0-10 \mathrm{~km}$. When the satellite ground track goes further to the open ocean, the tracking error becomes less significant. In this study, the tracking error is $\sim-3 \mathrm{~cm}$. This agrees well with the $-2.37 \mathrm{~cm}$ from Brenner et al. [1993].

\subsection{Collinear Analysis}

[38] The collinear differences, which are computed using altimeter-derived SSH profiles obtained along identical ground tracks but for different time periods, are next employed to estimate how the retracking system improves the altimeter data in coastal regions. The relative collinear offset between the profiles is $d H=H_{2}-H_{1}+\varepsilon$, where the $\mathrm{SSH}$ measurements at the same point, $H_{1}$ and $H_{2}$, occur at different times of cycles $t_{1}$ and $t_{2}$, and $\varepsilon$ is a random

Table 5. Descriptive Statistics of ERS-2 $20 \mathrm{~Hz}$ SSH Differences Before and After Retracking ( $d h=h_{r}-h_{g}$, Cycle 43)

\begin{tabular}{lccccc}
\hline $\begin{array}{c}\text { Distance to } \\
\begin{array}{c}\text { Coastline, } \\
\text { km }\end{array}\end{array}$ & $\begin{array}{c}\text { Number of } \\
\text { SSH }\end{array}$ & $\begin{array}{c}\text { Mean, } \\
\mathrm{m}\end{array}$ & $\begin{array}{c}\text { Max, } \\
\mathrm{m}\end{array}$ & $\begin{array}{c}\text { Min, } \\
\mathrm{m}\end{array}$ & STD, m \\
\hline $0-5$ & 6218 & -0.79 & 8.41 & -9.99 & 2.43 \\
$5-10$ & 8924 & -0.14 & 9.89 & -9.82 & 1.39 \\
$10-15$ & 9820 & -0.31 & 6.63 & -9.47 & 1.02 \\
$15-20$ & 9850 & -0.30 & 8.11 & -9.91 & 0.84 \\
$20-25$ & 10140 & -0.31 & 4.71 & -5.70 & 0.65 \\
$25-30$ & 9660 & -0.32 & 7.05 & -6.31 & 0.56 \\
\hline
\end{tabular}



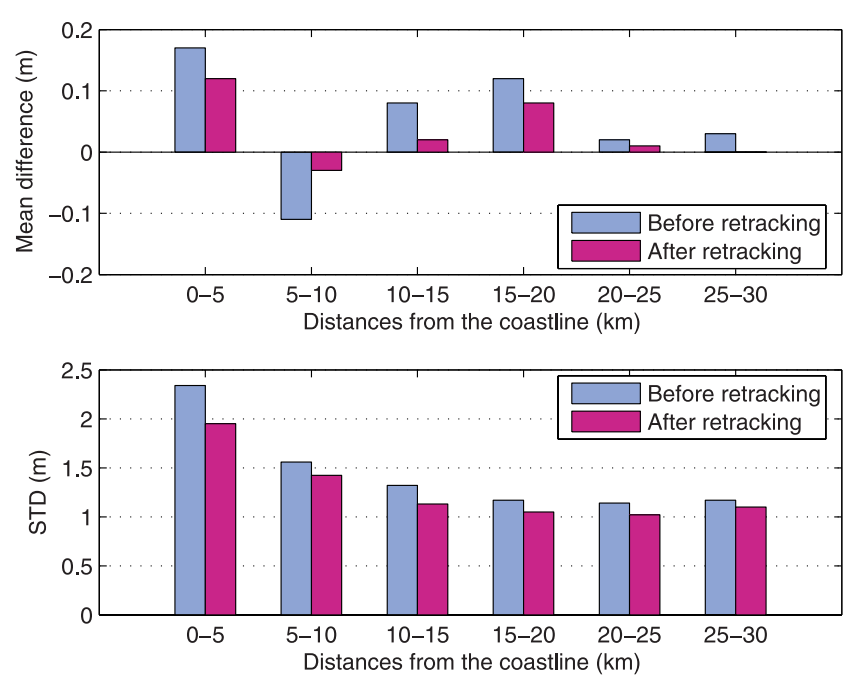

Figure 7. Mean differences (top) and STDs (bottom) of the collinear $20 \mathrm{~Hz} \mathrm{SSH}$ data of cycles 42 and 43 before and after retracking in six 5-km-wide distance bands, showing improvement in SSH data after retracking.

measurement error. In this study, since cycle 43 contains more orbits and thus more complete data coverage, it is chosen as a reference. SSH data from cycle 42 are then reduced to relevant points along ground tracks of cycle 43. The cross-track geoid gradient correction [cf. Wang and Rapp, 1991] is not applied, because data came from two adjacent cycles and the effects of the geoid slope can be neglected.

[39] The collinear differences remove the long-wavelength geoid and MDT as well as variations of the ocean surface, representing thus the amount of orbit error, altimeter range measurement error and temporal variations of the surface over oceans. In coastal regions, the random error also includes the tracking error caused by coastal topography. After removing the satellite orbit error, SSH data from repeat cycles can also be used to determine the mean sea surface [Wang and Rapp, 1991; Nerem, 1995]. Thus, the STD of $d H$ is used as a measure of the quality of a retracking algorithm's range estimate. If errors caused by waveform contamination can be removed by retracking, this will result in smaller STDs.

[40] The descriptive statistics of the collinear $20 \mathrm{~Hz} \mathrm{SSH}$ differences and STDs computed from cycles 42 and 43 were calculated both before and after retracking. The Results are plotted via six 5-km-wide distance bands in Figure 7. The STDs of $d H$ after retracking are smaller than STDs before retracking in all distance bands, particularly $0-15 \mathrm{~km}$ from the coastline. It is clear from this comparison that retracking improves the precision of altimeter range estimates in all distance bands but to different extents, especially in distances of $0-15 \mathrm{~km}$ (Figure 7). After $15 \mathrm{~km}$, the STDs after retracking are still slightly smaller than STD values before retracking, again indicating improvement.

\subsection{Evaluation of SSH Data Using Geoid Heights}

[41] The collinear analysis of SSH data along repeating tracks can determine the internal consistency (i.e., precision) of altimeter measurements. In order to assess the accuracy of the retracked data, and to determine how the retracked SSH profiles represent the true sea surface, an independently surveyed reference is required. The surface used is the AUSGeoid98 $2^{\prime} \times 2^{\prime}$ gravimetric geoid grid [Featherstone et al., 2001]. The difference between the $20 \mathrm{~Hz}$ SSHs before and after retracking and corresponding bi-spline-interpolated geoid height is computed along the ground tracks.

\subsubsection{Single-Track Retracked Results}

[42] Two ground tracks 21085 and 21364 were chosen. The $20 \mathrm{~Hz}$ SSHs and AUSGeoid98 geoid height profiles are plotted versus the along-track distance from the coastline in Figure 8. The typical near-land effects on unretracked SSH profiles begins at the along-track distance of $\sim 20 \mathrm{~km}$ for track 21085 (Figure 8, top) and $\sim 17.5 \mathrm{~km}$ for track 21364 (Figure 8, bottom). When approaching the coastline, unretracked SSHs decrease and then gradually increase, showing the V-patterns. The difference between the retracked and unretracked SSH heights can reach $\sim-5 \mathrm{~m}$ within $\sim 10 \mathrm{~km}$ for both tracks. In contrast, the geoid heights show a nearlinear trend within the whole distance. Since altimeterderived SSHs should provide the same geoid structure,
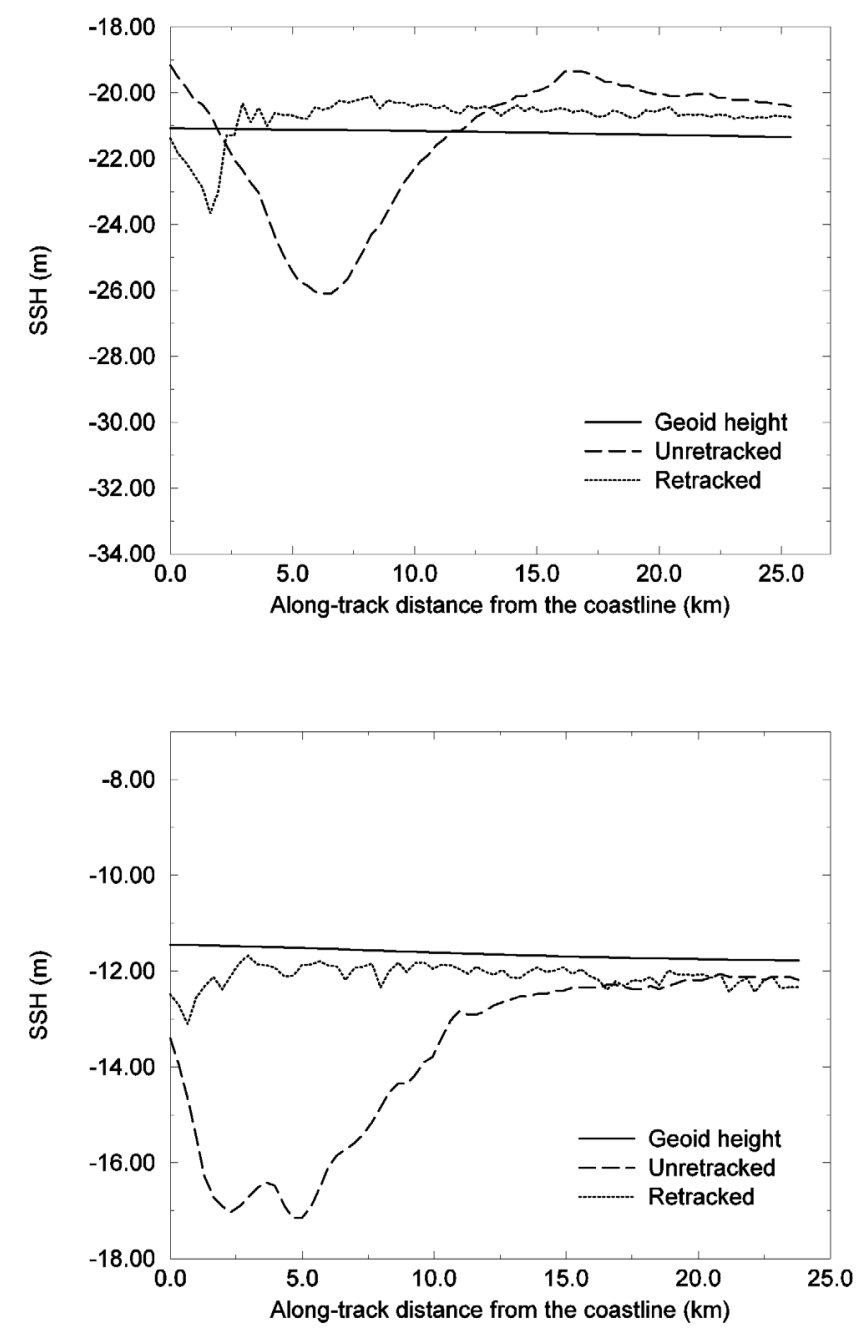

Figure 8. AUSGeoid98 height and SSH profiles (ERS-2, cycle 42) along ground tracks 21085 (top) and 21364 (bottom) before and after using the coastal retracking system. 

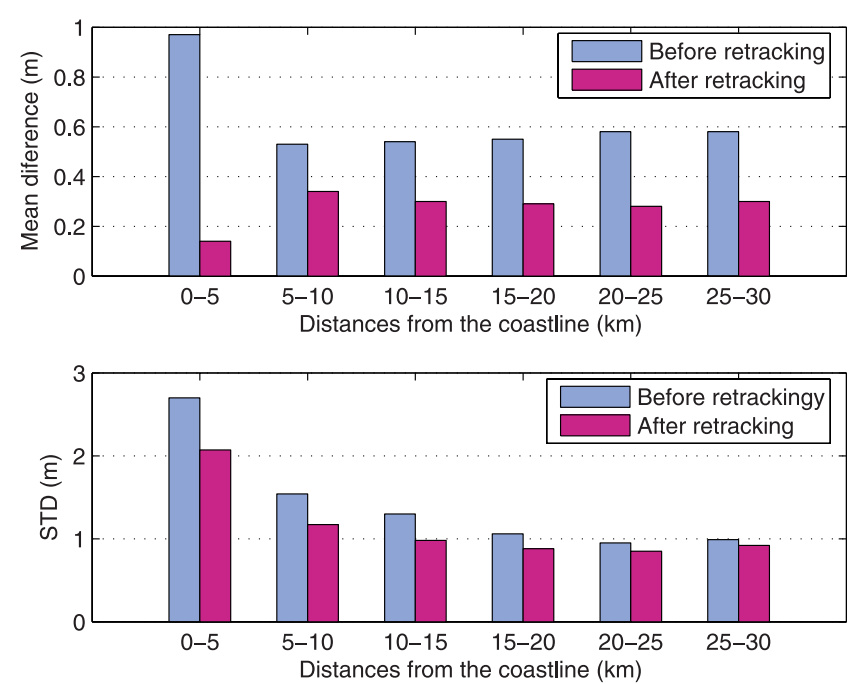

Figure 9. Mean (top) and STDs (bottom) of differences between AUSGeoid98 geoid heights and SSH data before and after retracking in six $5 \mathrm{~km}$ wide distance bands (cycle 42).

but different noise components from observations, such large differences with respect to the geoid clearly shows the general waveform contamination problem that exists in the untracked SSH data.

[43] In addition, according to the shape of the unretracked SSH profiles, the along-track SSH and corresponding geoid gradients were computed. The results from track 21085 (Figure 8, top) show that along-track AUSGeoid98 geoid gradients are small, from 9.2 to $10.9 \mathrm{ppm}(\mathrm{mm} / \mathrm{km})$ when the ground track is $0-7.5 \mathrm{~km}$ and $7.6-19.5 \mathrm{~km}$ from the coastline. For the same distances, unretracked-SSH gradients are $975.6 \mathrm{ppm}$ and $-509.2 \mathrm{ppm}$. Since the maximum geoid gradient is $\sim 150 \mathrm{ppm}$ in Australia [cf. Friedlieb et al., 1997; Featherstone et al., 2001], such SSH gradients are unrealistic and thus due to onboard tracking algorithm errors. Beyond $19.5 \mathrm{~km}$ from the coastline, AUSGeoid98 and unretracked-SSH gradients show commensurately small values of $12.5 \mathrm{ppm}$ and $-6.4 \mathrm{ppm}$. For track 21364 (Figure 8 , bottom), unretracked-SSH gradients are of $803.3 \mathrm{ppm}$ and $-363.8 \mathrm{ppm}$. The relative $\mathrm{SSH}$ gradients decrease to $\sim 16.0 \mathrm{ppm}$ after retracking for both tracks. Together, these results suggest as well that unretracked SSHs are in error within an along-track distance of $0-19.5 \mathrm{~km}$ from the coastline for tracks 21085 and 21364.

[44] Our retracking system, comprising several retrackers, can improve the SSH profile shoreward several kilometers, say $\sim 10-15 \mathrm{~km}$ from the coastline in Figure 8. Comparing the SSH profiles before and after retracking in Figure 8, the SSH profiles after retracking show a good agreement with the geoid-height profile from $\sim 2.5 \mathrm{~km}$ to $\sim 25 \mathrm{~km}$. However, it is important to note that the retracked SSH profiles cannot be completely closed to the coastline, where the land returns dominate the waveforms. In the case of tracks 21085 and 21364, SSHs to a distance of $\sim 2.5 \mathrm{~km}$ still cannot be recovered by retracking.

[45] It is also apparent from Figure 8 that the retracking has added some noise. These might be caused, firstly, by the shorter wavelength signal, which suggests that onboard tracking algorithm cannot follow temporal variations of the scattering surface; secondly, by unmodeled non-linear parameters that are neglected in this study (e.g., the skewness). Thus, a low-pass filtering procedure is still essential when using $20 \mathrm{~Hz}$ SSH data after retracking for the geophysical application in coastal regions. Alternatively, multiple collinear tracks can be stacked.

\subsubsection{Two Cycles of Waveform Retracking Results}

[46] For convenience of comparison, the mean and STD of the differences have been plotted via six 5-km-wide distance bands in Figure 9 for cycle 42 and Figure 10 for cycle 43. The STDs are large for both SSH data before and after retracking (Figures 9 and 10). This may be due to the temporal variations of the ocean surface, MDT included in the SSHs, and other incorrect corrections, such as ocean tides and wet tropospheric range corrections. Nevertheless, the retracked SSH data show a better precision than the unretracked data.

[47] For both cycles, our results show that both the mean and STD decrease when using retracked SSH data. The values of STD after retracking drop to $\sim 1 \mathrm{~m}$ when the distance to the coastline is $>10 \mathrm{~km}$ for cycle 42 (Figure 9) and $>5 \mathrm{~km}$ for cycle 43 (Figure 10). The STD before retracking drops to $<\sim 1 \mathrm{~m}$ only when the distance to the coastline is $>20 \mathrm{~km}$ for both cycles. The significant improvement occurs in distances $0-15 \mathrm{~km}$ from the coastline. Beyond $15 \mathrm{~km}$, though not statistically significant, there is still a decrease in the STD after retracking.

[48] These results indicate that the retracked SSH is more accurate in coastal regions beyond $\sim 5 \mathrm{~km}$ in general, while unretracked SSH data only a similar accuracy beyond $15-$ $20 \mathrm{~km}$. As such, retracked SSHs in coastal regions can be used to compute near-coastal geoidal undulations, coastal ocean circulation, gravity anomalies and ocean tides. Also results from Figures 9 and 10 show smaller STDs in all distance bands, implying that waveform retracking also has
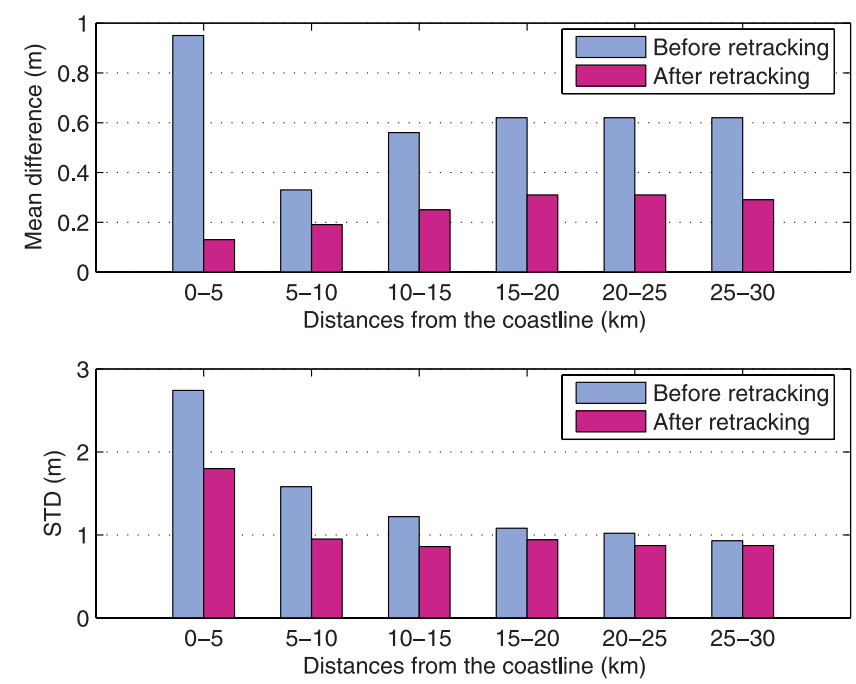

Figure 10. Mean (top) and STDs (bottom) of differences between AUSGeoid98 geoid heights and SSH data before and after retracking in six $5 \mathrm{~km}$ wide distance bands (cycle 43). 
the potential to improve SSHs beyond $30 \mathrm{~km}$ from the coastline and over open oceans.

\section{Discussion and Conclusions}

[49] In an effort to improve altimeter-derived SSH results in the well-known problematic coastal regions, this study has developed and tested a coastal retracking system to reprocess satellite radar altimeter waveform data for extracting improved SSH data sets in coastal regions. Investigations of waveform characteristics demonstrate that diverse waveform shapes exist around the Australian coast, and the retracking of $20 \mathrm{~Hz}$ waveform data can effectively remove most errors caused by coastal sea states and land-contamination. The development of the coastal retracking system includes design and investigation of algorithms, selection of threshold levels, estimation of biases among different retrackers, as well as the tests on the effectiveness of the system. Two cycles (43 and 44) of ERS-2 $20 \mathrm{~Hz}$ waveform data within $350 \mathrm{~km}$ from the Australian coast have been used for implementation of the system. The AUSGeoid98 model is used as a quasi-independent ground truth for some of the comparisons.

[50] Selection of the threshold retracking level was performed by comparing AUSGeoid98 "ground truth" with the SSH data before and after threshold retracking, in ten $15^{\circ} \times 15^{\circ}$ sub-areas and two 5-km-wide distance bands around Australia. Our results confirm that the 50\% threshold level is the best for open-ocean waveform, but is not an appropriate level for contaminated coastal waveforms. Instead, a varying threshold level, which is drops to $30 \%$ for some waveforms, gives a good agreement between the retracked SSH data and AusGeoid98. This value also agrees with that used by Brooks et al. [1997].

[51] Biases exit among retracked SSH data from different retracking algorithms. Biases have been analyzed and estimated by retracking ocean waveforms using two cycles of ERS-2 data. The bias between the SSH data retracked by the ocean and 5-parameter fitting algorithms is $-0.85 \pm$ $1.35 \mathrm{~cm}$, which is not statistically significant. However, the bias between the 50\%-threshold-retracked SSH data and the fitting algorithms (ocean and 5-parameter) is significant at $+56.35 \pm 5.84 \mathrm{~cm}$, which suggest that this bias must be estimated and applied to the data to obtain consistent results after retracking.

[52] Our waveform classification shows that $\sim 80 \%$ of contaminated waveforms in coastal regions present an ocean-like shape, but other shapes are found much closer to the coastline from this data set $(1.73-3.12 \mathrm{~km}$ on average), in particular high-peaked waveforms $(1.73 \mathrm{~km}$ from the coastline on average). The waveforms show different percentages when using different retrackers as a function of the sub-area along ground tracks. Retracking in Australian coastal regions shows that $\sim 80 \%-96 \%$ of waveforms can be retracked using a least squares iterative fitting algorithm, while $\sim 4 \%-17 \%$ of waveforms have to be retracked by the threshold algorithm.

[53] Of these waveforms retracked by fitting algorithms, $\sim 98 \%$ are fitted using the ocean model (or the 5-parameter model with a linear trailing edge) and the rest are fitted by the 5-parameter model with an exponential trailing edge and the 9-parameter model with either a linear trailing edge or an exponential trailing edge. This indicates that most waveforms in Australian coastal regions are mainly dominated by returns from a single scattering surface. It was also found that the need to use the threshold retracker decreases with increasing offshore distance (35\% of waveforms within $0-5$ $\mathrm{km}$ to $4 \%$ of waveforms within $5-10 \mathrm{~km})$. Beyond $10 \mathrm{~km}$, only $2 \%$ of waveforms are threshold retracked, indicating that the method developed to categorize coastal waveforms is effective.

[54] When comparing AUSGeoid98 with SSH data in Australian coastal regions, single-track comparisons show that the SSH gradients in the vicinity of the land before retracking are large, varying from $\sim 363.8-\sim-975.6 \mathrm{~mm} / \mathrm{km}$ over along-track distances of $4.7-19.5 \mathrm{~km}$, which is much larger than the maximum geoid gradient value of $\sim 150 \mathrm{~mm} / \mathrm{km}$ in Australia. After retracking, the SSH gradients decrease by $\sim 16.0 \mathrm{~mm} / \mathrm{km}$, agreeing well with the geoid gradient over the same distance. This quasi-independent validation, though ignoring DMT, strongly indicates that retracking improves the altimeter-derived SSH in coastal regions.

[55] In general, our coastal waveform retracking system has substantially improved and extended altimeter-derived SSHs $\sim 10-15 \mathrm{~km}$ shoreward in Australian coastal regions compared with unretracked SSH data, using AUSGeoid98 as a quasi-independent reference. As such, the altimeterderived SSH profiles are now believed to be more accurate beyond $\sim 5 \mathrm{~km}$ from the Australian coastline.

[56] These improved SSHs also show the same precision as those over open oceans, thus indicating a great potential to apply them to geodetic applications (e.g., tide determination) in coastal regions. However, $\mathrm{SSH}$ profiles $0-2.5 \mathrm{~km}$ from the coastline still cannot be recovered by the waveform retracking procedure at the same level of precision. This is attributed to a combination of severe contamination from land and inland water returns, the rougher sea states, as well as incorrect geophysical corrections in these near land areas.

[57] The improvement of the altimeter SSH in Australian coastal waters has demonstrated that our coastal waveform retracking system has the potential to be applied to other coastal regions, as well as to other satellite altimeter waveform data sets (e.g., Jason-1, Envisat and GFO). Higher accuracy of altimeter measurements in coastal regions will help realize a more complete coverage of altimetry missions for various scientific studies.

\section{Appendix A: Algorithms Used in the Coastal Waveform Retracking System}

\section{A1. Ocean Model}

[58] Following Brown [1977], the time series of the mean returned power waveform $P(t)$ measured by a satellite altimeter is analytically expressed in the time domain as [e.g., Hayne, 1980; Rodriguez, 1988; Rodriguez and Chapman, 1989; Amarouche et al., 2004]

$$
P(t)=P_{N}+\frac{1}{2} A\left[\operatorname{erf}\left(\frac{\tau}{\sqrt{2}}\right)+1\right] \exp \left[-d\left(\tau+\frac{d}{2}\right)\right]
$$


where $A$ is an amplitude scaling term, $P_{N}$ is the altimeter's thermal noise, and

$$
\begin{gathered}
\tau=\frac{t-t_{0}}{\sigma}-d \\
d=\left(\alpha-\frac{\beta^{2}}{4}\right) \sigma
\end{gathered}
$$

where $t$ is the time measured at the satellite such that $t=t_{0}$ corresponds to the range to the instantaneous sea level (averaged over the footprint) at nadir, $\sigma$ is the waveform rise-time (i.e., the information relative to the sea surface roughness through the $\mathrm{SWH}$ ), and

$$
\begin{gathered}
\alpha=\frac{4 c}{\gamma h} \frac{1}{(1+h / R)} \cos (2 \xi) \\
\beta=\frac{4}{\gamma}\left(\frac{c}{h} \frac{1}{(1+h / R)}\right)^{1 / 2} \sin (2 \xi)
\end{gathered}
$$

where $R \approx 6371005 \mathrm{~m}$ is the spherical radius of the Earth [Moritz, 1980], $h$ is the satellite altitude above the reference ellipsoid, $\gamma$ is a function of the antenna beam-width parameter $\theta$ defined by Brown [1977], and $\xi$ is the offnadir angle.

[59] The retracking process estimates five parameters of $P_{N}, A, t_{0}, \sigma$ and $\xi$. These estimates are performed making the measured waveform coincide with equation (A1) according to the iterative least squares fitting procedure.

\section{A2. Threshold Retracking}

[60] The empirical method of threshold retracking is based upon the dimensions of a rectangle about the amplitude $(A)$, width $(W)$, and center of gravity $(C O G)$ defined and computed using the off-center of gravity (OCOG) retracking method [e.g., Wingham et al., 1986; Partington et al., 1991; Davis, 1995]. The OCOG defines that the area of the rectangle equals that of the waveform, and the height of the $C O G$ is a half of the amplitude of the waveform. To reduce the effect of low-amplitude samples in front of the leading edge, the squares of the sample values are used in the computation. The equations used to compute $A, W$ and COG are given in Deng et al. [2002].

[61] The threshold value is then referenced to the amplitude [e.g., Bamber, 1994] or the maximum waveform sample [e.g., Zwally et al., 1990; Davis, 1997] estimate of the rectangle at $25 \%, 50 \%$, or $75 \%$ of the waveform amplitude. The selection of an optimum threshold level is critical, because the range is determined from it. The retracking gate estimate is determined by linearly interpolating between adjacent samples of a threshold crossing at steep part of the leading edge of the waveform. This algorithm maintains the same advantages as the OCOG, but it can determine a more accurate tracking gate position than the OCOG [Partington et al., 1991]. A disadvantage is that, like the OCOG method, it is not based on a physical model.

\section{A3. $\beta$-Parameter Retracking}

[62] Martin et al. [1983] develope the first retracking algorithm for processing altimeter return waveforms over continental ice sheets. This algorithm fits a 5- or 9-parameter function to the waveform reflected from one or two scattering surfaces over ice sheets. It is also known as $\beta$ parameter retracking or the NASA algorithm [e.g., Davis, 1995]. The general function fitting the radar returns is [Martin et al., 1983; Zwally et al., 1990]:

$$
y(t)=\beta_{1}+\sum_{i=1}^{n} \beta_{2 i}\left(1+\beta_{5 i} Q_{i}\right) P\left(\frac{t-\beta_{3 i}}{\beta_{4 i}}\right)
$$

where

$$
\begin{gathered}
Q_{i}= \begin{cases}0 & \text { for } t<\beta_{3 i}+0.5 \beta_{4 i} \\
t-\left(\beta_{3 i}+0.5 \beta_{4 i}\right) & \text { for } t \geq \beta_{3 i}+0.5 \beta_{4 i}\end{cases} \\
P(x)=\int_{-\infty}^{x} \frac{1}{\sqrt{2 \pi}} \exp \left(\frac{-q^{2}}{2}\right) d q
\end{gathered}
$$

where $n=1$ or 2 is the number of the ramp in the waveform that corresponds to single- or double-reflecting surfaces, respectively. Double ramps indicate that two distinct, nearly equidistant surfaces are tracked. The unknown parameters are the thermal noise level $\beta_{1}$, amplitude $\beta_{2 i}$, mid-point(s) on the leading edge of the waveform $\beta_{3 i}$, the waveform risetime $\beta_{4 i}$, and the slope of the trailing edge $\beta_{5 i}$. When $i=1$ in equation (A6), the corresponding function is 5 -parameter model.

[63] When the linear trailing edge is replaced by an exponential decay term [cf. Zwally et al., 1990], equation (A6) is adapted to give

$$
y(t)=\beta_{1}+\sum_{i=1}^{n} \beta_{2 i} \exp \left(-\beta_{5 i} Q_{i}\right) P\left(\frac{t-\beta_{3 i}}{\beta_{4 i}}\right)
$$

where

$$
Q_{i}= \begin{cases}0 & \text { for } t<\beta_{3 i}-2 \beta_{4 i} \\ t-\left(\beta_{3 i}+0.5 \beta_{4 i}\right) & \text { for } t \geq \beta_{3 i}-2 \beta_{4 i}\end{cases}
$$

This function can be used to fit the waveform with a fastdecaying trailing edge, which is caused by beam attenuation. It simulates the antennae attenuation as the pulse expands on the surface beyond the pulse-limited footprint.

\section{Appendix B: Comparison Between Ocean and 5-Parameter Models}

[64] Both the ocean (equation (A1)) and 5-parameter models (equations (A6) and (A9)) are based upon the Brown [1977] model. Comparison between them will give qualitative guidance to selecting an adequate fitting function for coastal retracking. In the trailing edge, the normal probability distribution $P(x)$ (or the erf function) is equal to unity 


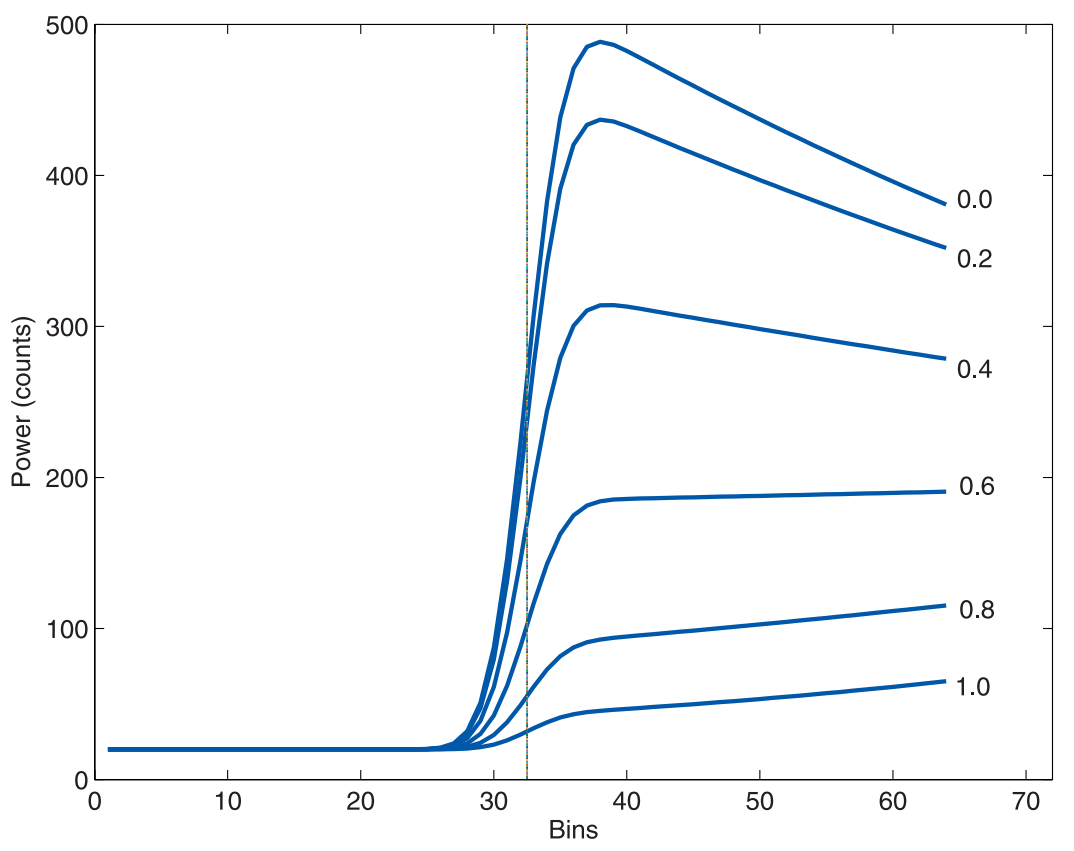

Figure B1. Effect of the off-nadir angle on the amplitude, leading edge, and especially the slope of the trailing edge, waveforms modeled by the ocean model $(\mathrm{SWH}=4 \mathrm{~m})$. Values of the off nadir angle are shown on the figure (in degrees).

for SWHs $<10 \mathrm{~m}$. Thus, in this region, equations (A1), and (A6), and (A9) can be written as $P_{t}(t), y_{t}(t)$, and $y_{t e}(t)$

$$
\begin{gathered}
\ln \left(P_{t}(t)-P_{N}\right)=\left[\ln (A)+\frac{d}{\sigma} t_{0}-\frac{d^{2}}{2}\right]-\frac{d}{\sigma} t \\
y_{t}(t)=\beta_{1}+\beta_{21}\left(1+\beta_{51} Q_{1}\right)
\end{gathered}
$$

$$
\ln \left(y_{t e}(t)-\beta_{e 1}\right)=\ln \left(\beta_{e 21}\right)-\beta_{e 51} Q_{1}
$$

where $d / \sigma, \beta_{51}$ and $\beta_{e 51}$ are the slope of the waveform trailing edge related to fitting functions.

[65] According to equation (A3), the slope $(d / \sigma)$ of the trailing edge in the ocean model is related to the physical

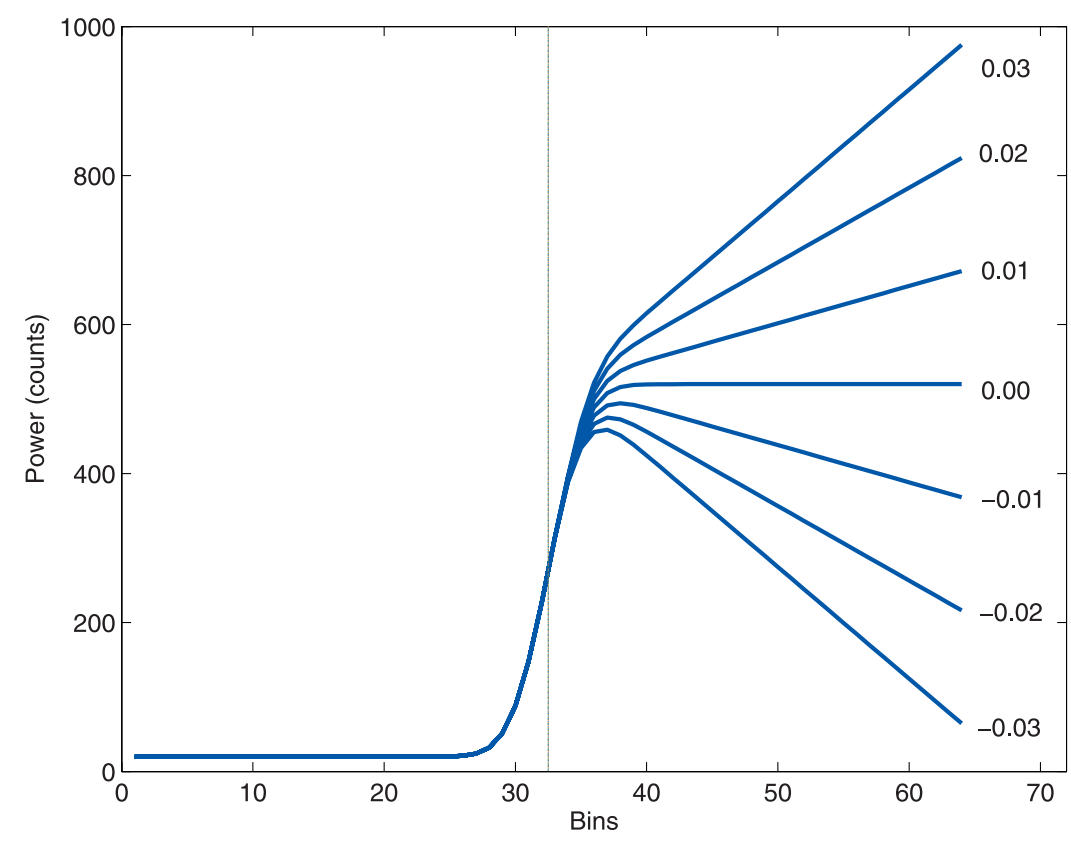

Figure B2. Effect of the parameter $\beta_{51}$ on the waveform trailing edge's slope and amplitude, waveforms modeled by the 5 -parameter function (linear trailing edge, $\beta_{21}=500$ counts). Values of $\beta_{51}$ are shown on the figure. 


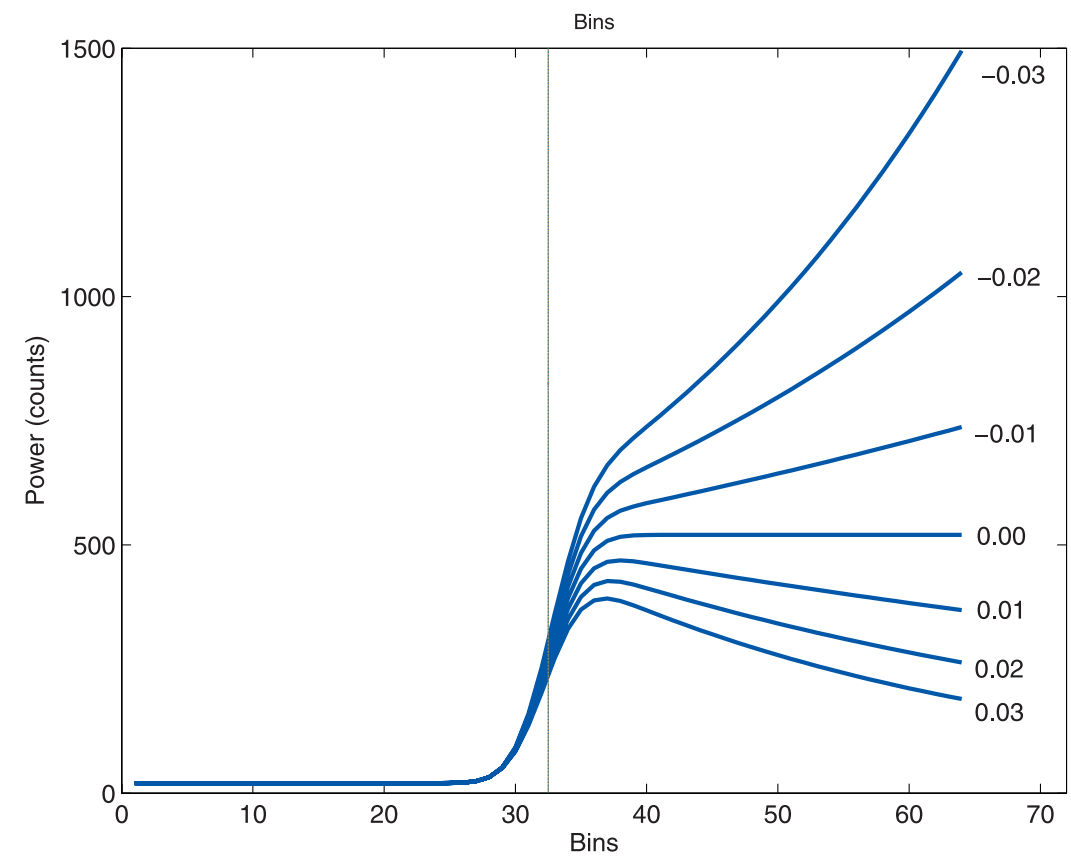

Figure B3. Effect of the parameter $\beta_{e 51}$ on the waveform trailing edge's slope and amplitude, waveforms modeled by the 5-parameter function (exponential decayed trailing edge, $\beta_{e 21}=500$ counts). Values of $\beta_{e 51}$ are shown on the figure.

parameters of the antenna gain pattern, the Earth's radius and the off-nadir angle $\xi$. Of these parameters, $\xi$ is important because it affects the slope of the trailing edge (Figure B1). From Figure B1, $\xi$ changes not only the slope of the trailing edge, but also the slope of the leading edge. The slope of the leading edge decreases with increasing $\xi$, while the slope of the trailing edge increases with increasing $\xi$. However, the location (or range to the instantaneous sea surface averaged over the footprint) of the mid-point on the leading edge does not change with varying $\xi$.

[66] The amplitude of the waveform is also affected (Figure B1), where the maximum power in the range window is $A=\sim 500$ counts when $\xi=0.0^{\circ}$. Since $\xi$ changes the decay of the trailing edge, it will affect the value of the automatic gain control (AGC) gate, and hence the AGCscaling of the waveform. Also from Figure B1, the slope of the trailing edge changes approximately linearly with $\xi$. The trailing edge's slope changes its direction at $\xi \approx 0.6^{\circ}$ (Figure B1). The reason is as the surface slope increases from zero, the pulse-limited footprint moves from the centre of the beam, and the leading edge and amplitude are attenuated by the antenna gain function. At steeper angles $\left(\xi>1^{\circ}\right)$, the attenuation becomes so great that the AGC loop can no longer compensate the loss in signal strength and loss of tracking occurs [e.g., Martin et al., 1983; Barrick and Lipa, 1985].

[67] The effect of $\beta_{51}$ and $\beta_{e 51}$ on the waveform using the 5 -parameter function is shown in Figure B2 (linear trailing edge and $\beta_{21}=500$ counts) and Figure B3 (exponential decayed trailing edge and $\beta_{e 21}=500$ counts), respectively. Values of $\beta_{51}$ and $\beta_{e 51}(-0.03-0.03)$ are chosen so that waveforms modeled by the 5-parameter function are comparable to those modeled by the ocean model (Figure B1). Two effects are evident. The values of $\beta_{51}$ and $\beta_{e 51}$ affect both the amplitude and slope of the trailing edge. From Figure B2, the power and slope of the linear trailing edge increase as the value of $\beta_{51}$ changes from -0.03 to 0.03 . The maximum power is $\sim 900$ counts when $\beta_{51}=0.03$. On the other hand, both the power and exponential decayed slope of the trailing edge decrease with increasing $\beta_{e 51}$ (Figure B3). The maximum power can be up to $\sim 1500$ counts when $\beta_{e 51}=0.03$, which is the largest power among Figures B1, B2, and B3. Similarly to the ocean model, the position of the mid-point on the leading edge is not influenced by variations of the slope in the trailing edge, though $\beta_{e 51}$ slightly changes the slope of the leading edge. Both trailing edges change their directions after $\beta_{51}=0.0$ or $\beta_{e 51}=0.0$.

[68] By comparison of results in Figures B1, B2, and B3, it is evident that different models have different slopes of the trailing edge. The results in Figure B2 are common with Figure B1, where the trailing edge region is nearly linear. The slope of the trailing edge in Figures B2 and B3 can vary to a greater extent than the slope of the ocean model (Figure B1). This makes it possible for the 5-parameter model to fit more complex waveforms over non-open-ocean surfaces. However, it can be seen that the slope of the trailing edge from the 5-parameter model (equations (B2) or (B3)) depends only on a non-physical (or empirical) parameter, $\beta_{51}$ (or $\beta_{e 51}$ ) rather than the antenna off-nadir angle $\xi$ (equation (B1)). It can thus be concluded that the 5parameter model is derived from ocean model (equation (A1)) or the Brown [1977] model.

[69] Acknowledgments. Curtin University of Technology International Postgraduate Research and Postgraduate Scholarships funded this research. We thank the European Space Agency (ESA) for providing the ERS-1 waveform data. We thank Phillipa Berry (De Montfort University, UK), Cheinway Hwang (National Chiao Tung University, Taiwan), Jon 
Kirby (Curtin University of Technology, Australia), Graham Quartly (Southampton Oceanography Centre, UK), O.P. Knudsen and O.B. Andersen (Danish National Space Centre, Demark), J.D. Fairhead (University of Leeds, UK), Ronald Brooks (NASA, USA) and George Hayne (NASA, USA) for providing some references and numerous useful discussions. We also thank the anonymous reviewers and the editor (James Kirby) for their comments on this manuscript.

\section{References}

Amarouche, L., P. Thibaut, O. Z. Zanife, J.-P. Dumont, P. Vincent, and N. Steunou (2004), Improving the Jason-1 ground retracking to better account for attitude effects, Mar. Geod., 27, 171-197.

Andersen, O. B., and P. Knudsen (2000), The role of satellite altimetry in gravity field modelling in coastal areas, Phys. Chem. Earth A, 25(1), $17-$ 24.

Anzenhofer, M., C. K. Shum, and M. Renstch (2000), Coastal altimetry and applications, report, Ohio State Univ., Columbus.

Bamber, J. L. (1994), A digital elevation model of the Antarctic ice sheet derived from ERS-1 altimeter data and comparison with terrestrial measurements, Ann. Glaciol., 20, 48-54.

Barrick, D. E., and B. J. Lipa (1985), Analysis and interpretation of altimeter sea echo, Adv. Geophys., 27, 61-100.

Brenner, A. C., C. J. Koblinsky, and H. J. Zwally (1993), Postprocessing of satellite return signals for improved sea surface topography accuracy, J. Geophys. Res., 98(C1), 933-944.

Brooks, R. L., D. W. Lockwood, and J. E. Lee (1997), Land effects on TOPEX radar altimeter measurements on Pacific Rim coastal zones, NASA WFF Publ. (Available at http://topex.wff.nasa.gov/)

Brown, G. S. (1977), The average impulse response of a rough surface and its applications, IEEE Trans. Antennas Propag., 25(1), 67-74.

Buchanan, C. (1991), Bathymetric 30 arc second grid of the Australian region [CD-ROM], Geosci. Aust., Canberra, Australia.

Chelton, D. B., J. C. Ries, B. J. Haines, L.-L. Fu, and P. S. Callahan (2001) Satellite altimetry, in Satellite Altimetry and Earth Sciences: A Handbook of Techniques and Applications, edited by L.-L. Fu and A. Cazenave, pp. 1-132, Elsevier, New York.

Davis, C. H. (1995), Growth of the Greenland Ice Sheet: A performance assessment of altimeter retracking algorithms, IEEE Trans. Geosci. Remote Sens., 33(5), 1108-1116.

Davis, C. H. (1997), A robust threshold retracking algorithm for measuring ice-sheet surface elevation change from satellite radar altimeter, IEEE Trans. Geosci. Remote Sens., 35(4), 974-979.

Deng, X. (2004), Improvement of geodetic parameter estimation in coastal regions from satellite radar altimetry, Ph.D. thesis, 248 pp., Curtin Univ. of Technol., Perth, Australia.

Deng, X., W. E. Featherstone, C. Hwang, and P. A. M. Berry (2002), Estimation of contamination of ERS-2 and POSEIDON satellite radar altimetry close to the coasts of Australia, Mar. Geod., 25(4), 249-271.

Dong, X., P. Moore, and R. Bingley (2002), Absolute calibration of the TOPEX/POSEIDON altimeter using UK tide gauges, GPS, and precise local geoid-differences, Mar. Geod., 25, 189-204.

Dunbar, P. (2000), DS759.2 - Terrain base, global 5-minute ocean depth and land elevation, Natl. Geophys. Data Cent., Boulder, Colo. (Available at http://dss.ucar.edu/datasets/ds759.2/)

Fairhead, J. D., C. M. Green, and M. E. Odegard (2001), Satellite-derived gravity having an impact on marine exploration, The Leading Edge, 20 , $873-876$

Featherstone, W. E., J. F. Kirby, A. H. W. Kearsley, J. R. Gilliland, G. M. Johnston, J. Steed, R. Forsberg, and M. G. Sideris (2001), The AUSGeoid98 geoid model of Australia: data treatment, computations and comparisons with GPS-levelling data, J. Geod., 75, 13-330.

Fernandes, M. J., L. Bastos, and M. Antunes (2003), Coastal satellite altimetry - methods for data recovery and validation, in Gravity and Geoid 2002, edited by I. N. Tziavos, pp. 302-307, Dep. of Surv. and Geod., Aristotle Univ. of Thessaloniki, Thessaloniki.
Friedlieb, O. J., W. E. Featherstone, and M. C. Dentith (1997), A WGS84AHD profile over the darling fault, Western Australia, Geomatics Res. Australasia, 67, 17-32.

Hayne, G. S. (1980), Radar altimeter mean return waveform from nearnormal-incidence ocean surface scattering, IEEE Trans. Antennas Propag., 28(5), 687-692.

Hayne, G. S, and D. W. Hancock III (1990), Corrections for the effects of significant wave height and attitude on Geosat radar altimeter measurements, J. Geophys. Res., 95(C3), 2837-2842.

Levitus, S. (1982), Climatological atlas of the World Ocean, Natl. Oceanic Atmos. Admin., Prof. Pap., 13, 1-180.

Li, D. R. (1988), The Error and Reliability Theory, 331 pp., Surv. and Mapp., Beijing, China.

Mantripp, D. (1996), Radar altimetry, in The Determination of Geophysical Parameters From Space, edited by N. E. Fancey, I. D. Gardiner, and R. A. Gardiner, pp. 119-171, Inst. of Phys., London, UK

Martin, T. V., H. J. Zwally, A. C. Brenner, and R. A. Bindschadler (1983), Analysis and retracking of continental ice sheet radar altimeter waveforms, J. Geophys. Res., 88(C3), 1608-1616.

Moritz, R. S. (1980), Advanced Physical Geodesy, 500 pp., Wichmann, Karlsruhe.

Nerem, R. S. (1995), Measuring global mean sea level variations using TOPEX/POSEIDON altimeter data, J. Geophys. Res., 100(C12), $25,135-25,151$

NRSC (1995), Altimeter waveform product alt.wap compact user guide, $P F-U G-N R L-A L-0001,32$ pp., U.K. Process. and Arch. Facil., UK.

Partington, K. C., W. Cudlip, and C. G. Rapley (1991), An assessment of the capability of the satellite radar altimeter for measuring ice sheet topographic change, Int. J. Remote Sens., 12(3), 585-609.

Quartly, G. D., and M. A. Srokosz (2001), Analyzing altimeter artifacts: statistical properties of ocean waveforms, J. Atmos. Oceanic Technol., 18, 2074-2091.

Rodriguez, E. (1988), Altimetry for non-Gaussian oceans: height biases and estimation of parameters, J. Geophys. Res., 93(C11), 14,107-14,120.

Rodriguez, E., and B. Chapman (1989), Exacting ocean surface information from altimeter returns: the deconvolution method, J. Geophys. Res., 94(C7), 9761-9778.

Strub, P. L., and C. James (1997), Satellite comparisons of eastern boundary currents: resolution features in "coastal" oceans, paper presented at Monitoring the Oceans in the 2000s: An Integrated Approach, Biarritz, France.

Thom, B. G. (1984), Geomorphic research on the coast of Australia: A preview, in Coastal Geomorphology in Australia, edited by B. G. Thom, pp. 1-15, Elsevier, New York.

Wang, Y.-M., and R. H. Rapp (1991), Geoid gradients for Geosat and Topex/Poseidon repeat ground tracks, Rep. 408, 26 pp., Ohio State Univ., Columbus.

Wessel, P., and W. H. F. Smith (1996), A global, self-consistent, hierarchical, high-resolution shoreline database, J. Geophys. Res., 101(B4), $8741-8743$

Wingham, D. J., C. G. Rapley, and H. Griffiths (1986), New techniques in satellite tracking systems, in Proceedings of IGARSS' 88 Symposium, Zurich, Switzerland, September, pp. 1339-1344, IEEE Press, Piscataway, N. J.

Zwally, H. J., A. C. Brenner, J. A. Major, and R. A. Bindschadler (1990), Satellite radar altimetry over ice, volumes 1, 2, and 4, NASA Ref. Publ., 1233

X. Deng, Discipline of Civil, Surveying and Environmental Engineering, University of Newcastle, University Drive, Callaghan, NSW 2308, Australia. (xiaoli.deng@newcastle.edu.au)

W. E. Featherstone, Western Australian Centre for Geodesy, Curtin University of Technology, GPO Box U1987, Perth, WA 6845, Australia. 